Article

\title{
Synthesis and Catalytic Application of Knölker-Type Iron Complexes with a Novel Asymmetric Cyclopentadienone Ligand Design
}

\author{
Christian A. M. R. van Slagmaat ${ }^{1}$, Khi Chhay Chou ${ }^{1}$, Lukas Morick $^{1}$, Darya Hadavi ${ }^{2}$, \\ Burgert Blom ${ }^{1}$ and Stefaan M. A. De Wildeman ${ }^{1, *}$ \\ 1 Faculty of Science and Engineering, Maastricht University, 6167 RD Geleen, The Netherlands; \\ c.vanslagmaat@maastrichtuniversity.nl (C.A.M.R.v.S.); k.chou@student.maastrichtuniversity.nl (K.C.C.); \\ lmorick@gmail.com (L.M.); burgert.blom@maastrichtuniversity.nl (B.B.) \\ 2 Maastricht MultiModal Molecular Imaging Institute (M4I), Maastricht University, 6229 ER Maastricht, \\ The Netherlands; d.hadavi@maastrichtuniversity.nl \\ * Correspondence: s.dewildeman@maastrichtuniversity.nl
}

Received: 31 August 2019; Accepted: 17 September 2019; Published: 22 September 2019

\begin{abstract}
Asymmetric catalysis is an essential tool in modern chemistry, but increasing environmental concerns demand the development of new catalysts based on cheap, abundant, and less toxic iron. As a result, Knölker-type catalysts have emerged as a promising class of iron catalysts for various chemical transformations, notably the hydrogenation of carbonyls and imines, while asymmetric versions are still under exploration to achieve optimal enantio-selectivities. In this work, we report a novel asymmetric design of a Knölker-type catalyst, in which the $\mathrm{C}_{2}$-rotational symmetric cyclopentadienone ligand possesses chiral substituents on the 2- and 5-positions near the active site. Four examples of the highly modular catalyst design were synthesized via standard organic procedures, and their structures were confirmed with NMR, IR, MS, and polarimetry analysis. Density functional theory (DFT) calculations were conducted to elucidate the spatial conformation of the catalysts, and therewith to rationalize the influence of structural alterations. Transfer- and $\mathrm{H}_{2}$-mediated hydrogenations were successfully established, leading to appreciable enantiomeric excesses (ee) values up to 70\%. Amongst all reported Knölker-type catalysts, our catalyst design achieves one of the highest ee values for hydrogenation of acetophenone and related compounds.
\end{abstract}

Keywords: asymmetric hydrogenation; homogeneous catalysis; iron; structural design; conformational analysis; NMR spectroscopy; DFT

\section{Introduction}

The importance of asymmetric catalysis is emphasized by the Nobel Prize of 2001 awarded to Noyori and Knowles, for their contributions to asymmetric hydrogenations [1,2]. Their efforts harvested pivotal discoveries and developments, such as the enantioselective synthesis of the anti-Parkinson drug Levodopamine [3]. Catalysts for these transformations generally rely on precious metals such as ruthenium or rhodium, but the ever-increasing scale of global application in combination with environmental concerns demands the development of new catalysts based on first-row transition metals; preferably cheap, abundant, and less toxic iron [4-6].

Fortunately, many developments of iron-based catalysts have been conducted meanwhile by the groups of Gao [7], Morris [8], Chirik [9] and Milstein [10], to name a few, and their sophisticated ligand structures often show highly enhanced catalytic properties compared to simple iron salts or iron pentacarbonyl [11]. However, perhaps the most versatile class of iron catalysts is derived from $\eta 4$-(cyclopentadienone) iron tricarbonyl complexes, which are often called "Knölker-type complexes". 
Although iron compounds of such kind were synthesized for the first time in 1953 by Reppe and Vetter [12], and revisited by several groups subsequently [13], it was the pioneering work of Knölker et al. upon the delicate chemistry of $\eta_{5}$-(1,3-bis(trimethylsilyl)-4,5,6,7-tetrahydro-2H-inden-2-one)iron tricarbonyl (1a) [14-19], for which its trivial name "Knölker's complex" became generally accepted in literature. Ever since the discovery of Knölker's complex possessing catalytic activity for the hydrogenation of polarized double bonds by Casey and Guan in 2007 [20], this bifunctional iron catalyst has received tremendous attention in modern research [13].

The modes of interaction between a Knölker-type catalyst and a substrate usually rely on an 'outer-sphere' coordination mechanism, as shown in Scheme 1 for hydrogenation [21-23]. When starting from a Knölker-type complex (1), it first undergoes mono-decarbonylation by treatment with a base, $\mathrm{Me}_{3} \mathrm{NO}$, or UV-light [24], to afford an unsaturated 16e species with a vacant site (2). Via the heterolytic addition of (a) hydrogen (donor), followed by heterolytic cleavage, the metal center is oxidized from $\mathrm{Fe}(0)$ to $\mathrm{Fe}(\mathrm{II})$, while the $\eta_{4}$-cyclopentadienone ligand turns into an aromatic $\eta_{5}$-hydroxycyclopentadiene moiety. As such, the bifunctional active species (3) is formed, featuring protic binding site on the ligand, and a hydridic site on the iron. A polarized unsaturated substrate (e.g., a ketone) can then associate onto these hydrogen atoms, initiating hydrogen transfer to furnish reduction product (e.g., alcohol), while 2 is formed back.

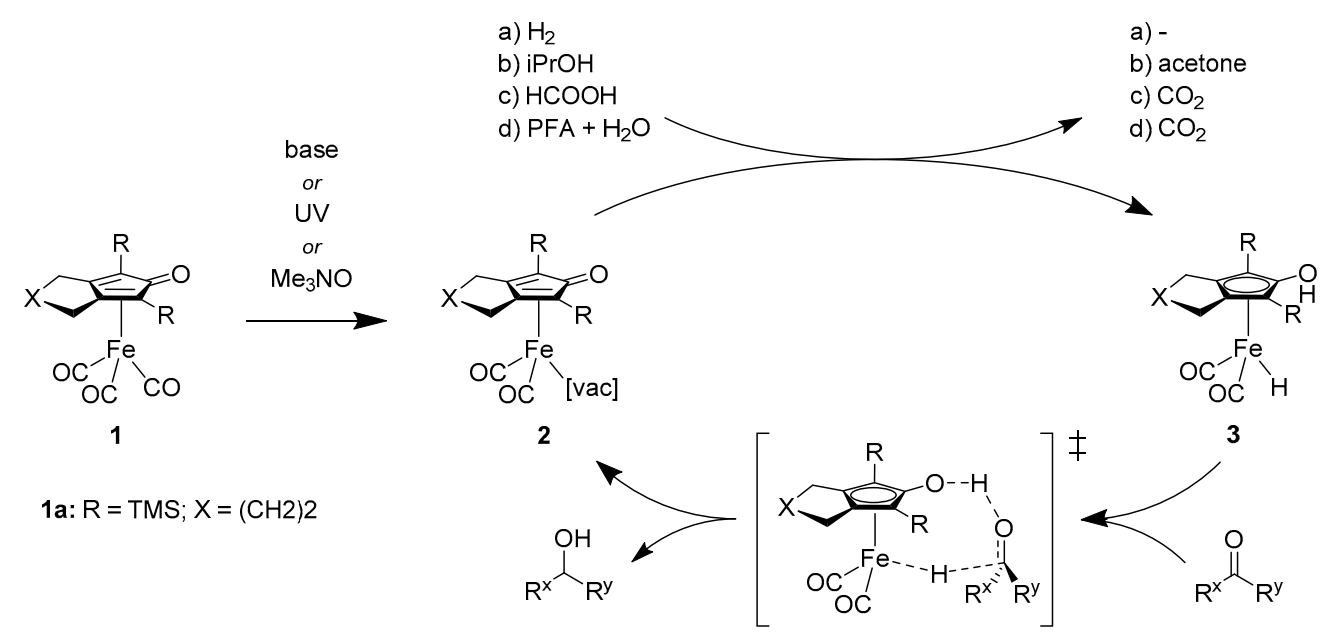

Scheme 1. Activation procedures and the catalytic cycle of a Knölker-type catalyst for the hydrogenation of ketones, featuring the "concerted outer-sphere mechanism" for hydrogen transfer. Suitable hydrogen donors can be dihydrogen, isopropyl alcohol, formic acid, and paraformaldehyde with water.

Following associative interactions conform this mechanism; the catalyst was found applicable in both transfer and pressure hydrogenation [20,25,26], Oppenauer oxidation [27], reductive amination [28], water-gas-shift-reactions [29], electro-reductions [30], alkylations [31], photocatalysis [32], and enantioselective dual catalysis typically for allylic alcohols [33-38] with formidable results. The capabilities of Knölker-type catalysts in asymmetric catalysis for normal ketones and imines have also been explored [39], however, their performance regarding enantioselectivity are generally found mediocre, as well for the corresponding ruthenium-based complexes (see Figure 1). Hence, in order to make Knölker-type catalysts industrially more competitive for the production of asymmetric fine chemicals, we considered further development a necessity.

To our knowledge, the first asymmetric catalyst of such kind is reported by Yamamoto et al. [40], who designed ruthenium complexes derived from spirocyclic C-arylribosides. Shortly after, cyclopentadienone metal complexes with different substituents on the 2,5-positions, and with an enantiopure carbon center in the cyclic backbone of the ligand were developed by the group of Wills $[25,41]$. In these early examples the ligand design did not allow complete blockage of one face of the cyclopentadienone moiety, leading to diastereomeric mixtures of the complexes, and therefore to rather low enantio-selectivities in catalysis. 


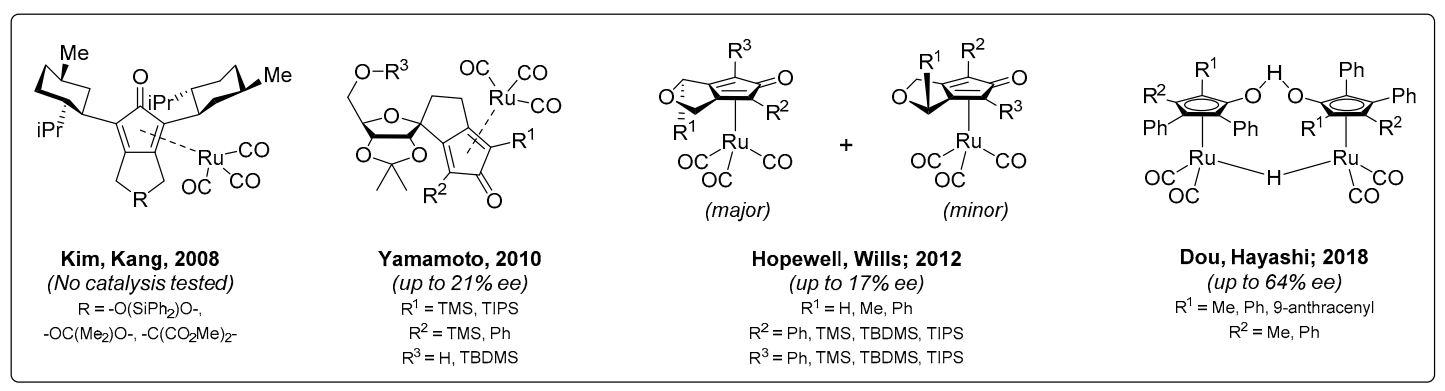

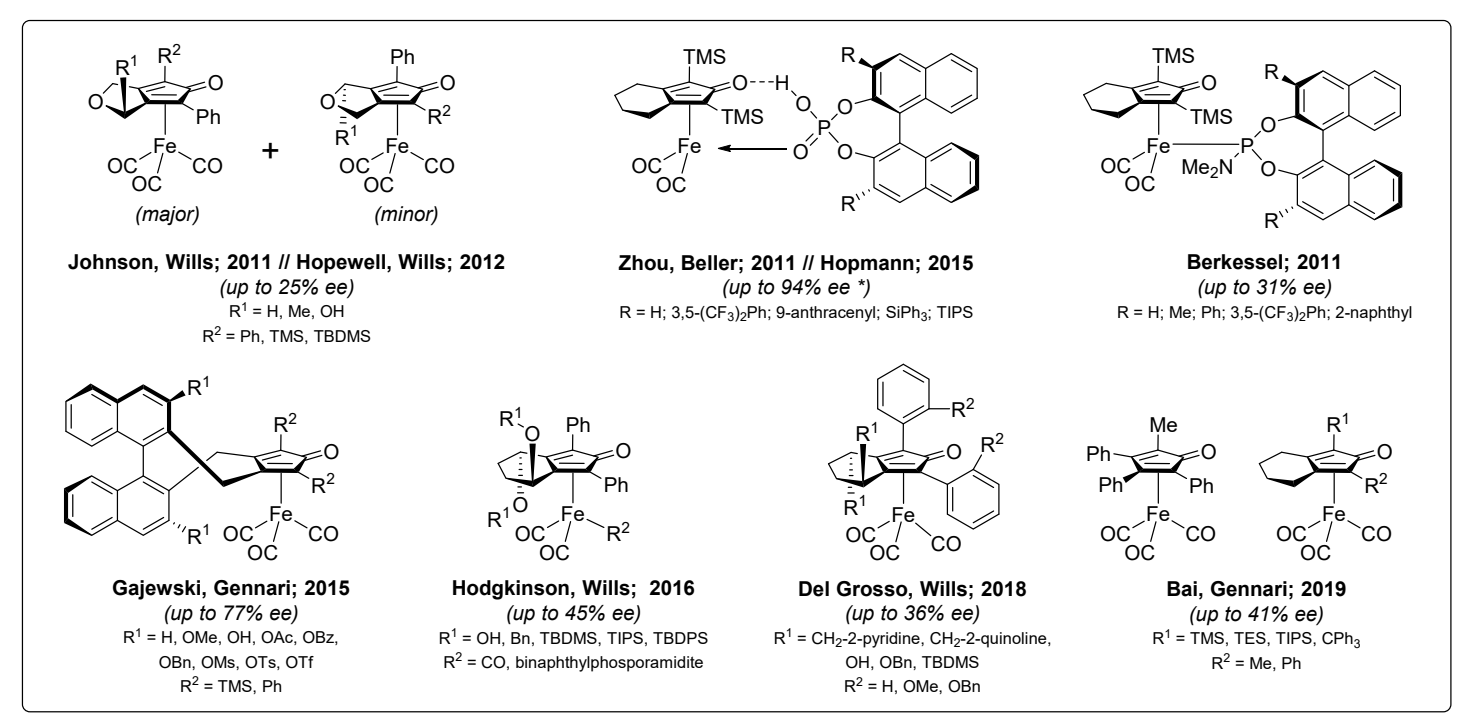

Figure 1. Overview of reported structures of asymmetric cyclopentadienone-ligated metal tricarbonyl complexes, featuring ruthenium (top panel) and iron (bottom panel), and their best enantioselectivity in asymmetric hydrogenation. * This result concerns the hydrogenation of imines.

In later years, this problem was circumvented with the use of ligands featuring a $\mathrm{C}_{2}$-rotational symmetry axis along the catalytically functional carbonyl bond, because for such a design coordination of the metal to either face of the ligand will lead to the same complex. As such, higher catalytic enantioselectivities could be achieved [42,43], with the best example featuring BINOL-derived cyclopentadienone ligand provided by Gajewski et al. [44-46].

Alternatively, racemic mixtures of asymmetric ruthenium [47] and iron catalysts [48] with different 2,5-substituents were separated using preparative chiral HPLC chromatography, yielding batches of both pure enantiomers. These catalyst versions achieved appreciable enantioselectivities for certain substrates, however, they was not high enough to make them industrially relevant.

Meanwhile, different concepts had also emerged which derived their chirality from a different chemical source to induce enantio-selectivity using a symmetric Knölker-type complex. Binaphthyl phosphoric acids were employed as co-catalysts by the Beller group, and they achieved outstanding enantiomeric excesses (ee) values over $90 \%$. However, their system is only applicable to imines [49-52], quinoxalines and benzoxazines [53]. Binaphthyl phosphoramides were coordinated to a symmetric Knölker catalyst [24], as well as asymmetric iron complexes [42]. Furthermore, enzymatic approaches have also been explored, for example iron-catalyzed hydrogenation in combination with dynamic kinetic resolution using Candida antarctica Lipase B [54,55], but also covalent bonding of Knölker-type catalysts into a Streptadivin enzyme [56]. However, the latter example rendered low to moderate enantioselectivities.

By in-depth study of all available literature on asymmetric (cyclopentadienone)metal catalysts, we deduced that desirable structural aspects are $\mathrm{C}_{2}$-rotary symmetry of the ligand, and having the chirality-inducing moieties closer located to the active site of the catalyst, in order to envision improved 
enantioselectivity by Knölker-type catalysts. Therefore, we hypothesize that a cyclopentadienone ligand, bearing two identical enantiopure substituents on the 2- and 5-position with $R, R$ or $S, S$ orientations only, could be a suitable design for this goal. To our knowledge, only one example of such a design is reported for a ruthenium complex by Kim et al. [57], which possesses enantiopure menthyl substituents. Surprisingly, the complexes in this work were not tested in any catalytic reaction, and successive research upon ligand designs of this kind has been dormant for over a decade until now.

\section{Results and Discussion}

\subsection{Design, Synthesis and Characterization of the Pre-Ligands and Catalysts}

In our pursuit of designing a novel asymmetric Knölker-type catalyst, bearing a $\mathrm{C}_{2}$ - rotational symmetric cyclopentadienone ligand with chiral centers on the 2,5-positions (4), we considered two conventional synthesis strategies by applying retrosynthetic analysis, as shown in Scheme 2. Herein, Route A describes the formation of the desired iron complex from an iron carbonyl precursor and a 3,4-aryl appended cyclopentadienone (5) [58], which could be obtained from the double aldol condensation [59] of an $R, R$ or $S, S$ diastereopure $\beta, \beta^{\prime}$-substituted acetone (6), and an aril (7). Alternatively, via Route B the iron complex with the desired structural features (4) can also be derived from the $2+2+1$ cycloaddition of an iron carbonyl precursor with a tethered dialkyne [60], containing identically enantiopure groups on the termini (8). Such dialkyne pre-ligands can be obtained via coupling reactions of enantiopure terminal alkynes (9) with a dihalide (10) [61-64].
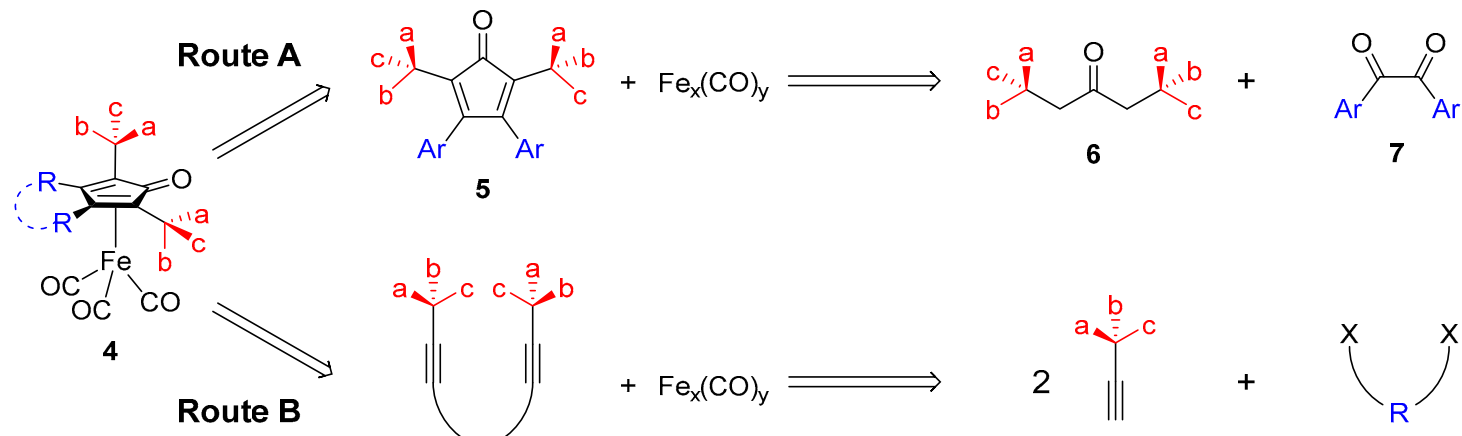

5

6

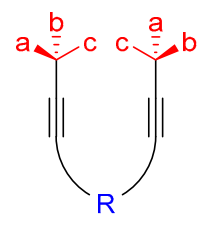

8

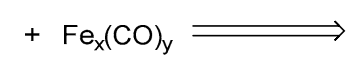

Scheme 2. Retro-syntheses of an iron cyclopentadienone complex, with optically active substituents on the 2,5-positions of the ligand.

Although syntheses of compounds in accordance with the structure of 6 have been reported $[65,66]$, the acquisition of such diastereopure product in decent yields remains a significant challenge. On the contrary, enantiopure terminal alkynes are easier to synthesize, because they possess only one chiral center, and are readily available from commercial sources. For these reasons we selected Route B to target the first examples of our asymmetric catalyst design. Herein, we considered enantiopure 1-substituted prop-2-yn-1-ols as the ideal synthon, because the possible combinations of 1-substituents and applicable alcohol protection groups offer a broad variety of structures to tune the envisioned catalyst. In addition, the dihalide synthon allows structural modularity in the backbone of the cyclopentadienone ligand.

Considering the nature of the reaction steps in the total synthesis, a proper protection group for the alcohol of the starting material is required to ensure chemical orthogonality against the strong base required in the next step for alkynic proton abstraction, while a successful double $\mathrm{C}-\mathrm{C}$ coupling with the dihalide is a requisite to furnish the pre-ligand. In addition, a microwave-assisted procedure for the complexation onto iron pentacarbonyl giving high yields was recently published [67]. These facts led to the establishment of the total synthesis described in Scheme 3. 


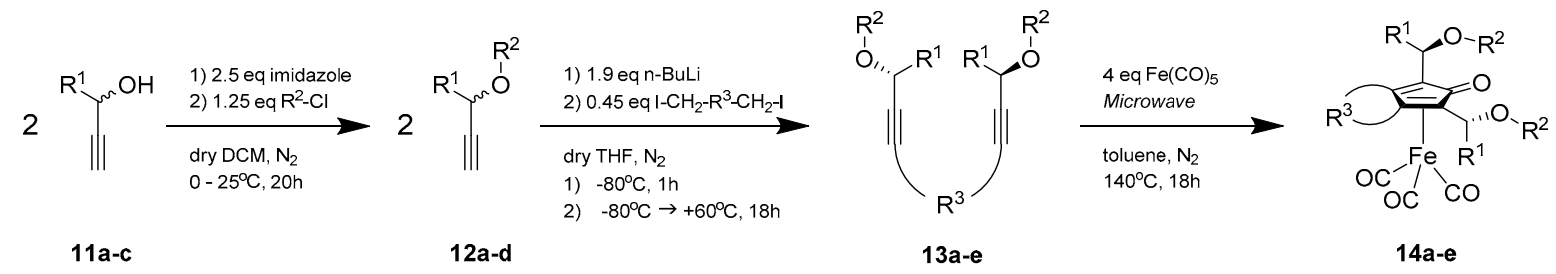

Scheme 3. Total synthesis of a novel asymmetric iron cyclopentadienone complex series from enantio-pure 1-substituted prop-2-ynols. $\mathrm{R}^{1}=\mathrm{Me}, \mathrm{Ph} ; \mathrm{R}^{2}=\mathrm{TIPS}, \mathrm{TBDPS} ; \mathrm{R}^{3}=\left(\mathrm{CH}_{2}\right)_{4},\left(\mathrm{CH}_{2}\right)_{3}$.

As the first example, R-but-3-yn-2-ol (11a) was protected with a triisopropylsylil (TIPS) group using Corey's conditions [68], affording the desired silyl ether product (12a) in 93\% yield, and complete preservation of the enantiopurity was confirmed by chiral GC-fid and polarimetry (Table 1).

However, the subsequent coupling reaction to produce the pre-ligand 13a proved to be far more challenging. Although complete and selective abstraction of the alkynic proton be established in THF using $\mathrm{nBuLi}$, we experienced through numerous attempts that only iodides are sufficient leaving groups for the alkyl dihalide reagent to achieve appreciable conversion. A strict temperature program featuring the addition of $\mathrm{nBuLi}$ at $-80^{\circ} \mathrm{C}$ to react for $1 \mathrm{~h}$ allows complete deprotonation, followed by the addition of 1,4-diiodobutane still at $-80^{\circ} \mathrm{C}$, after which the resulting mixture is kept at $60{ }^{\circ} \mathrm{C}$ overnight to drive the reaction. Moreover, delicate excess amounts of reagents (i.e., 12a $>\mathrm{nBuLi}>>1$,4-diiodobutane) were essential to acquire bis-coupled product, and to minimize the remainder of mono-coupled intermediate. Although having trace amounts of mono-coupled species in the crude product was practically inevitable, separation over a long silica column ultimately provided chemo-pure 13a in a commendable $89 \%$ yield. Polarimetry indicated enantiomeric excess of the $R, R$-diastereomer being present in 13a, but no absolute diastereo-purity could be ensured, since the pre-ligand is too heavy for GC-fid, and diastereomers of 13a could not be distinguished in NMR.

Table 1. Obtained yields and enantiomeric properties of the starting materials, silylated building blocks, pre-ligands, and catalysts.

\begin{tabular}{|c|c|c|c|c|c|c|}
\hline Compound & $\mathbf{R}^{1}$ & $\mathbf{R}^{2}$ & $\mathbf{R}^{3}$ & $\begin{array}{l}\text { Isolated } \\
\text { Yield (\%) }\end{array}$ & $\begin{array}{l}\text { Enantiomeric } \\
\text { Configuration }\end{array}$ & $\begin{array}{l}\text { Specific } \\
\text { Rotation }\end{array}$ \\
\hline 11a & $\mathrm{Me}$ & - & - & $\mathrm{n} / \mathrm{a}$ & $R$ & $\mathrm{n} / \mathrm{d}$ \\
\hline $11 b$ & $\mathrm{Ph}$ & - & - & $\mathrm{n} / \mathrm{a}$ & $R$ & $\mathrm{n} / \mathrm{d}$ \\
\hline 11c & $\mathrm{Me}$ & - & - & $\mathrm{n} / \mathrm{a}$ & rac & 0 \\
\hline $12 a$ & $\mathrm{Me}$ & TIPS & - & 92.7 & $R$ & +96.1 \\
\hline $12 b$ & $\mathrm{Me}$ & TBDPS & - & 91.3 & $R$ & +288.3 \\
\hline $12 \mathrm{c}$ & $\mathrm{Ph}$ & TIPS & - & 85.5 & $R$ & -14.8 \\
\hline $12 d$ & $\mathrm{Me}$ & TIPS & - & 76.3 & rac & 0 \\
\hline $13 a$ & $\mathrm{Me}$ & TIPS & $\left(\mathrm{CH}_{2}\right)_{4}$ & 89.1 & $R, R$ & +122.6 \\
\hline $13 b$ & $\mathrm{Me}$ & TBDPS & $\left(\mathrm{CH}_{2}\right)_{4}$ & 38.7 & $R, R$ & +364.1 \\
\hline $13 c$ & $\mathrm{Ph}$ & TIPS & $\left(\mathrm{CH}_{2}\right)_{4}$ & 60.8 & $R, R$ & -37.0 \\
\hline $13 d$ & $\mathrm{Me}$ & TIPS & $\left(\mathrm{CH}_{2}\right)_{3}$ & 70.3 & $R, R$ & +131.9 \\
\hline $13 e$ & $\mathrm{Me}$ & TIPS & $\left(\mathrm{CH}_{2}\right)_{4}$ & 66.8 & rac & 0 \\
\hline $14 a$ & $\mathrm{Me}$ & TIPS & $\left(\mathrm{CH}_{2}\right)_{4}$ & 51.4 & $R, R$ & +16.5 \\
\hline $14 b$ & $\mathrm{Me}$ & TBDPS & $\left(\mathrm{CH}_{2}\right)_{4}$ & 33.8 & $R, R$ & +62.5 \\
\hline $14 c$ & $\mathrm{Ph}$ & TIPS & $\left(\mathrm{CH}_{2}\right)_{4}$ & 18.2 & $R, R$ & -107.5 \\
\hline $14 d$ & $\mathrm{Me}$ & TIPS & $\left(\mathrm{CH}_{2}\right)_{3}$ & 51.9 & $R, R$ & +8.4 \\
\hline $14 \mathrm{e}^{1}$ & $\mathrm{Me}$ & TIPS & $\left(\mathrm{CH}_{2}\right)_{4}$ & 48.2 & rac & 0 \\
\hline
\end{tabular}

${ }^{1} \mathbf{1 4}$ e serves as a collective abbreviation for all obtained diastereo-isomers in this reaction.

The complexation reaction of 13a with $\mathrm{Fe}(\mathrm{CO})_{5}$ in a closed system at $140{ }^{\circ} \mathrm{C}$ by microwave irradiation was carried on nevertheless, and the expected increase of pressure by $\mathrm{CO}$ release was indeed observed within few hours. From the retrieved dark suspension a bright yellow solid was isolated through column chromatography, and identified as a Knölker-type complex by the characteristic IR 
absorptions in the region of $1980-2070 \mathrm{~cm}^{-1}$ for the iron-bound carbonyl vibration modes, plus the vibration of $1630 \mathrm{~cm}^{-1}$ for the ligand's ketone. In addition, detected masses of $675.31648 \mathrm{Da}$ and 697.29835 Da, corresponding to the protonated species and sodium ion, respectively, exhibited the isotopic patterns of a mono-iron species. Altogether, with an optical rotation in polarimetry observed, and with thorough ${ }^{1} \mathrm{H}$ - and ${ }^{13} \mathrm{C}-\mathrm{NMR}$ analysis (vide infra), the successful synthesis of enantiopure complex 14a with 51\% yield was confirmed (see Appendix A).

The optimal reaction conditions and purification procedures found for all three synthetic steps towards 14a were also applicable for certain structural variations of the building blocks and reagents (Table 1). Protection of 11a with tert-butyldiphenyl silyl (TBDPS) group, followed by dicoupling onto 1,4-diiodobutane and complexation with iron pentacarbonyl afforded the more bulky complex $\mathbf{1 4 \mathbf { b }}$. 1-phenylprop-2-yn-1-ol (11b) was demonstrated as well to be an eligible building block for silylation, and subsequent nBuLi-mediated coupling, which ultimately led to sterically- and electronically altered complex 14c. Silyl ether 12a was also coupled to 1,3-diiodopropane, to finally afford complex 14d, which possesses a smaller five-membered ring as backbone of its ligand. Furthermore, the use of racemic but-3-yn-2-ol 11c in the total synthesis led to the diastereomeric mixture 14e. In total, the syntheses of complex series 14a-d (Figure 2) give rise to a structural variation in each of $R^{1}, R^{2}$, and $R^{3}$, respectively, enabling the study of the influence of each separate R-group on the structural conformation of the ligand, as well as enantioselectivity in catalysis (vide infra).
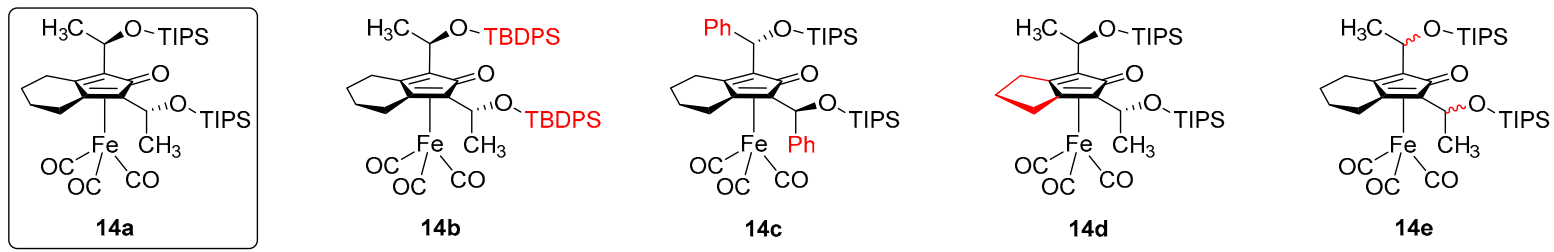

Figure 2. Structures of the asymmetric Knolker-type complexes synthesized in this work. 14a serves as the base case complex, while the fragments of $\mathbf{1 4 b}-\mathbf{e}$ marked in red are structural alterations upon 14a.

NMR analysis was conducted as the main technique to verify the success of each step in the total catalyst syntheses. In ${ }^{1} \mathrm{H}-\mathrm{NMR}$ (Figure 3, top), upon silylation of 11a-c the disappearance of the alcohol signal, and the rise of silyl-appended hydrocarbon signals around $1 \mathrm{ppm}$ were observed for 12a-textbfd. The introduction of the alkyl tether via the coupling reaction then provided two characteristic peaks between 1.5 and 2.5 ppm for 13a-textbfc (different signals for 13d). Finally, in ${ }^{13} \mathrm{C}$-NMR the characteristic signals of Knölker-type complexes were observed for iron-bound carbonyls between 200-210 ppm, and the cyclopentadienone carbonyl in the proximity of $170 \mathrm{ppm}$ (Figure 3, bottom).

However, the most significant effects were observed upon changing the molecular architecture of the linear dialkyne into a bicyclic ring structure via the $2+2+1$ cyclo-addition with iron pentacarbonyl. As such, a spatial confinement of the bulky chiral substituents was created, while the $\mathrm{C}_{2}$-rotary symmetry of the newly formed cyclopentadienone ligand is broken by coordination of iron to one plane. This inflicted an intriguing splitting phenomenon with remarkably high differences in chemical shift $(\Delta \delta)$ for most of the signals in both ${ }^{1} \mathrm{H}$ - and ${ }^{13} \mathrm{C}-\mathrm{NMR}$. For the molecular fragments being closer to the centers of asymmetry, notably $\mathrm{R}_{1}$, the methine groups of the 2,5-substituents, and the cyclopentadienone carbons, $\Delta \delta$ generally appeared to be larger (see the section 'Materials and Methods', Appendix A, and the Supplementary Materials for in-depth details). 

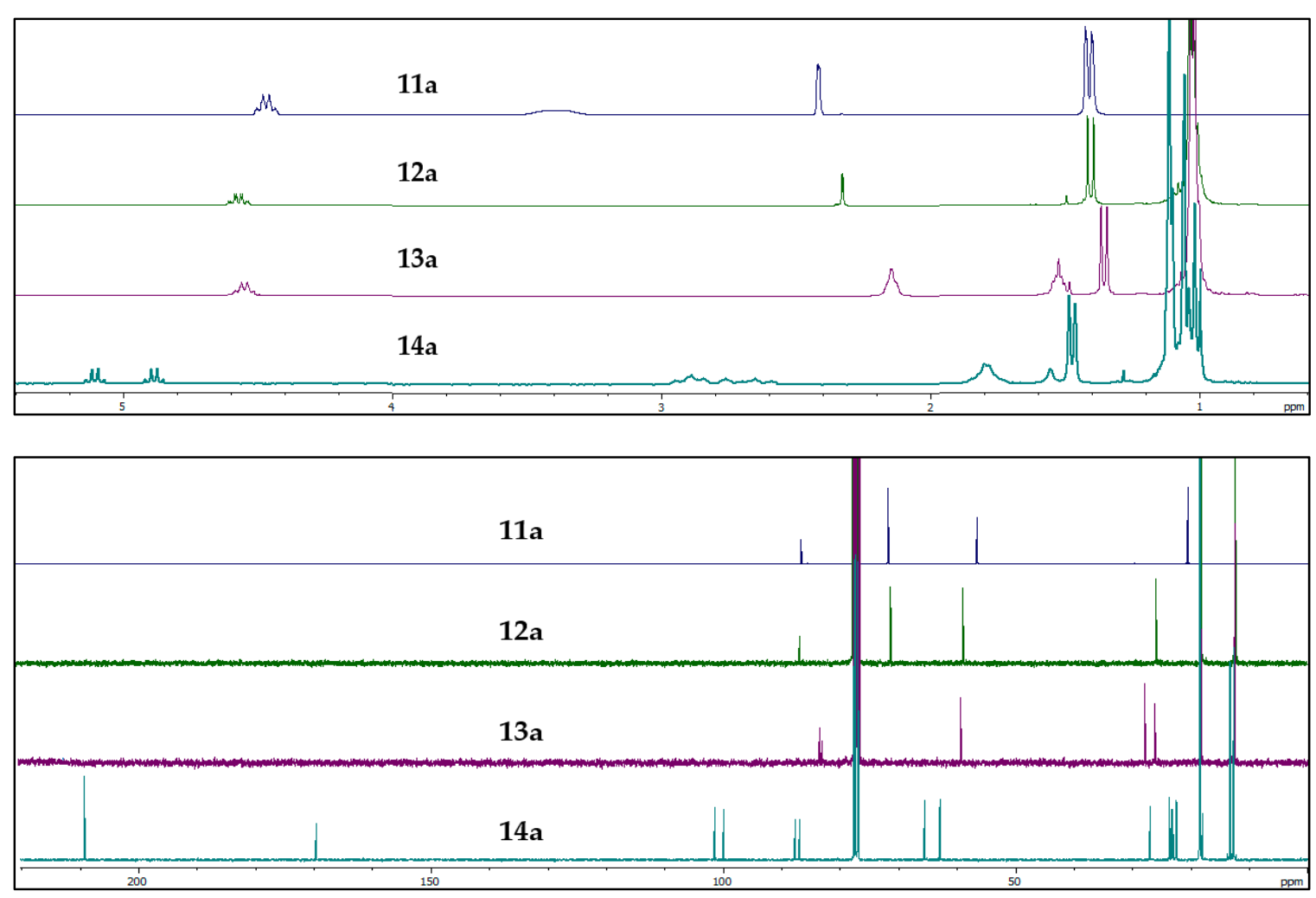

Figure 3. ${ }^{1} \mathrm{H}-\mathrm{NMR}$ (top) and ${ }^{13} \mathrm{C}-\mathrm{NMR}$ (bottom) spectra of compounds 11a, 12a, 13a, and 14a in $\mathrm{CDCl}_{3}$.

Similar signal patterns in the NMR spectra for complexes $\mathbf{1 4 b - d}$ were observed as well, but with different chemical shifts and $\Delta \delta$ splits, of which the most noteworthy ones are listed in Tables 2 and 3. Although these spectroscopic values are to an extent subjected to the electronic nature of the molecular surroundings of their corresponding atoms, we believe that they are also affected by the dihedral rotation of the chiral 2,5-substituents, as a result from structural variations in $R^{1}, R^{2}$, and $R^{3}$. Therefore, the comparison of complexes $\mathbf{1 4 b} \mathbf{b} \mathbf{d}$ with 14a could provide useful insights for each separate structural deviation.

In general, a higher $\Delta \delta$ for a signal in NMR is in accordance with a slower and less facile spatial movement of the corresponding molecular group [69]. Although a clear trend for such peak segregation is not easily recognized by taking all represented split signals into account, some observed NMR signals may still be linked to possible structural properties. The heavier and sterically more encumbered 2,5-substituents of $\mathbf{1 4} \mathrm{c}$ are expected to exhibit a more restricted dihedral rotation, which is in agreement with the increased values for $\Delta \delta$ in ${ }^{13} \mathrm{C}-\mathrm{NMR}$.

On the other hand, $\mathbf{1 4 d}$ possesses a fused five-membered ring as backbone of the ligand, which is narrower than the fused six-membered ring of $\mathbf{1 4 a}$, while $\mathrm{R}^{1}$ and $\mathrm{R}^{2}$ are identical for these complexes. Remarkably, all $\Delta \delta$ values (except for the methyl group in ${ }^{1} \mathrm{H}-\mathrm{NMR}$ ) are significantly smaller than the values observed for 14a. This result suggests a considerably more facile rotation of the 2,5-substituents for 14d, which may be enabled by the narrower backbone of the ligand, and highlights the unexpectedly significant effect of the $\mathrm{R}^{3}$-group.

Regarding $\mathrm{R}^{1}$, no statement on the effect of certain silyl groups can be declared yet, whereas the observed differences in $\Delta \delta$ values for $\mathbf{1 4 b}$ are not understood at this moment, and the steric difference (e.g., cone angles) between TIPS and TBDPS are rather similar [70]. For a better understanding, a larger scope of alcohol protection groups for $\mathrm{R}^{1}$ should be included in a future study. 
Table 2. Observed chemical shifts and values of $\Delta \delta$ of characteristic signal splitting in ${ }^{1} \mathrm{H}-\mathrm{NMR}$ spectroscopy for the synthesized iron complexes in $\mathrm{CDCl}_{3}$.

\begin{tabular}{|c|c|c|c|c|}
\hline \multirow{3}{*}{ Complex } & \multicolumn{4}{|c|}{${ }^{1} \mathrm{H}-\mathrm{NMR}$} \\
\hline & \multicolumn{2}{|c|}{ Methine } & \multicolumn{2}{|c|}{ Methyl } \\
\hline & $\delta(\mathrm{ppm})$ & $\Delta \delta(\mathrm{Hz})$ & $\delta($ ppm) & $\Delta \delta(\mathrm{Hz})$ \\
\hline $14 a$ & 4.99 & 66.3 & 1.47 & 6.4 \\
\hline $14 b$ & 4.82 & 85.7 & 1.32 & 6.4 \\
\hline $14 c$ & 5.94 & 52.7 & - & - \\
\hline 14d & 4.89 & 28.1 & 1.47 & 18.8 \\
\hline
\end{tabular}

Table 3. Observed chemical shifts and values of $\Delta \delta$ of characteristic signal splitting in ${ }^{13} \mathrm{C}-\mathrm{NMR}$ spectroscopy for the synthesized iron complexes in $\mathrm{CDCl}_{3}$.

\begin{tabular}{|c|c|c|c|c|c|c|c|c|}
\hline \multirow{3}{*}{ Complex } & \multicolumn{8}{|c|}{${ }^{13} C-N M R$} \\
\hline & \multicolumn{2}{|c|}{ 3,4-Cp } & \multicolumn{2}{|c|}{ 2,5-Cp } & \multicolumn{2}{|c|}{ Methine } & \multicolumn{2}{|c|}{ Methyl } \\
\hline & $\delta($ ppm) & $\Delta \delta(\mathrm{Hz})$ & $\delta($ ppm) & $\Delta \delta(\mathrm{Hz})$ & $\delta($ ppm) & $\Delta \delta(\mathrm{Hz})$ & $\delta($ ppm) & $\Delta \delta(\mathrm{Hz})$ \\
\hline $14 a$ & 100.5 & 113.9 & 87.2 & 61.2 & 64.1 & 194.6 & 25.2 & 261.2 \\
\hline $14 \mathrm{~b}$ & 100.6 & 74.5 & 86.0 & 110.4 & 64.3 & 98.0 & 25.1 & 237.1 \\
\hline $14 c$ & 99.8 & 156.4 & 87.7 & 248.0 & 69.2 & 223.6 & - & - \\
\hline $14 d$ & 105.5 & 60.6 & 88.4 & 28.0 & 64.5 & 52.6 & 27.6 & 5.2 \\
\hline
\end{tabular}

The occurrence of such notable signal splitting in NMR spectra, as a result from the structural asymmetry in these complexes, prompted us to investigate the diastereo-isomeric mixture 14e, which was obtained from racemic building block 11c through the total iron complex synthesis (Scheme 3). Herein, 12d and 13e were analyzed and compared with their structural contenders from enantio-pure sources, to confirm that their spectroscopic properties and masses are identical, but no optical rotation in polarimetry can be detected (Table 1).

However, upon complexation of $13 \mathbf{e}$ with $\mathrm{Fe}(\mathrm{CO})_{5}$ a statistical mixture all possible diastereo-isomers is expected, comprising the asymmetric $R, R$-complex 14a and its enantiomer $S, S$-complex 14a', as well as two meso-isomers: $R, S$-complex $14 \mathrm{f}$ and $S, R$-complex $14 \mathrm{~g}$, which are not enantiomers of each other (Scheme 4). Because enantiomers 14a and 14a' exhibit identical molecular environments and conformations, though mirrored, they cannot be distinguished from each other by spectroscopy. In contrast, the pairs of chiral centers of symmetric compounds $14 \mathrm{f}$ and $\mathbf{1 4} \mathrm{g}$ have opposite optical configurations pertaining to the iron core, which is expected to give different dihedral rotations of their 2,5-substituents. Therefore, the diastereomerically racemic mixture 14e should display three sets of signals in NMR spectroscopy, in theory.
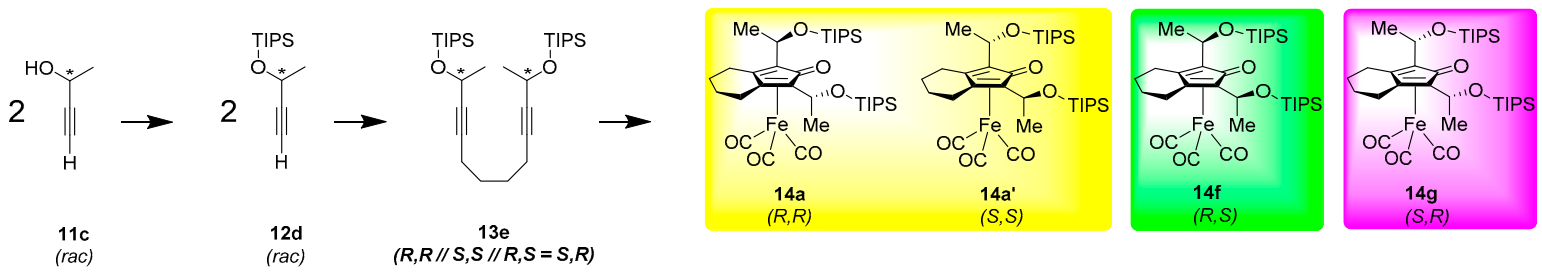

Scheme 4. Total synthesis of a diastereomeric mixture of (cyclopentadienone)iron complexes derived from racemic but-3-yn-2-ol. Each colored box indicates a (group of) diastereo-isomer(s) that can be distinguished by spectroscopic analysis. The collective mixture of $14 \mathbf{a}+\mathbf{1 4} \mathbf{a}^{\prime}+\mathbf{1 4 f} \mathbf{f}(+\mathbf{1 4} \mathbf{g})$ is denoted as 14e.

The actual NMR spectra of 14e, however, only revealed two sets of signals, of which one set belongs to both 14a and 14a', which is in accordance with the absence of optical rotation in polarimetry. The other set comprises non-split signals that are characteristic for a symmetric Knölker-type complex 
(see Supplementary Materials). In ${ }^{13} \mathrm{C}-\mathrm{NMR}$, the new peaks at $209.35 \mathrm{ppm}$ and $169.58 \mathrm{ppm}$ were assigned to the iron-bound carbonyls and the cyclopentadienone carbonyl, respectively. Clear singular peaks at $146.87 \mathrm{ppm}, 101.39 \mathrm{ppm}$, and $87.76 \mathrm{ppm}$ were also observed for the other pair of cyclopentadienone carbons and the methine carbons, respectively (Figure 4, bottom). The ${ }^{1} \mathrm{H}-\mathrm{NMR}$ spectrum shows through the doublet of quartets for the methine protons of 14a and 14a' in the region of 5.0-5.2 ppm another singular quartet at $5.08 \mathrm{ppm}$, in agreement with a symmetric species within $14 \mathbf{e}$ (Figure 4, top). These observations evidence that only three out of four expected diastereo-isomers are formed.
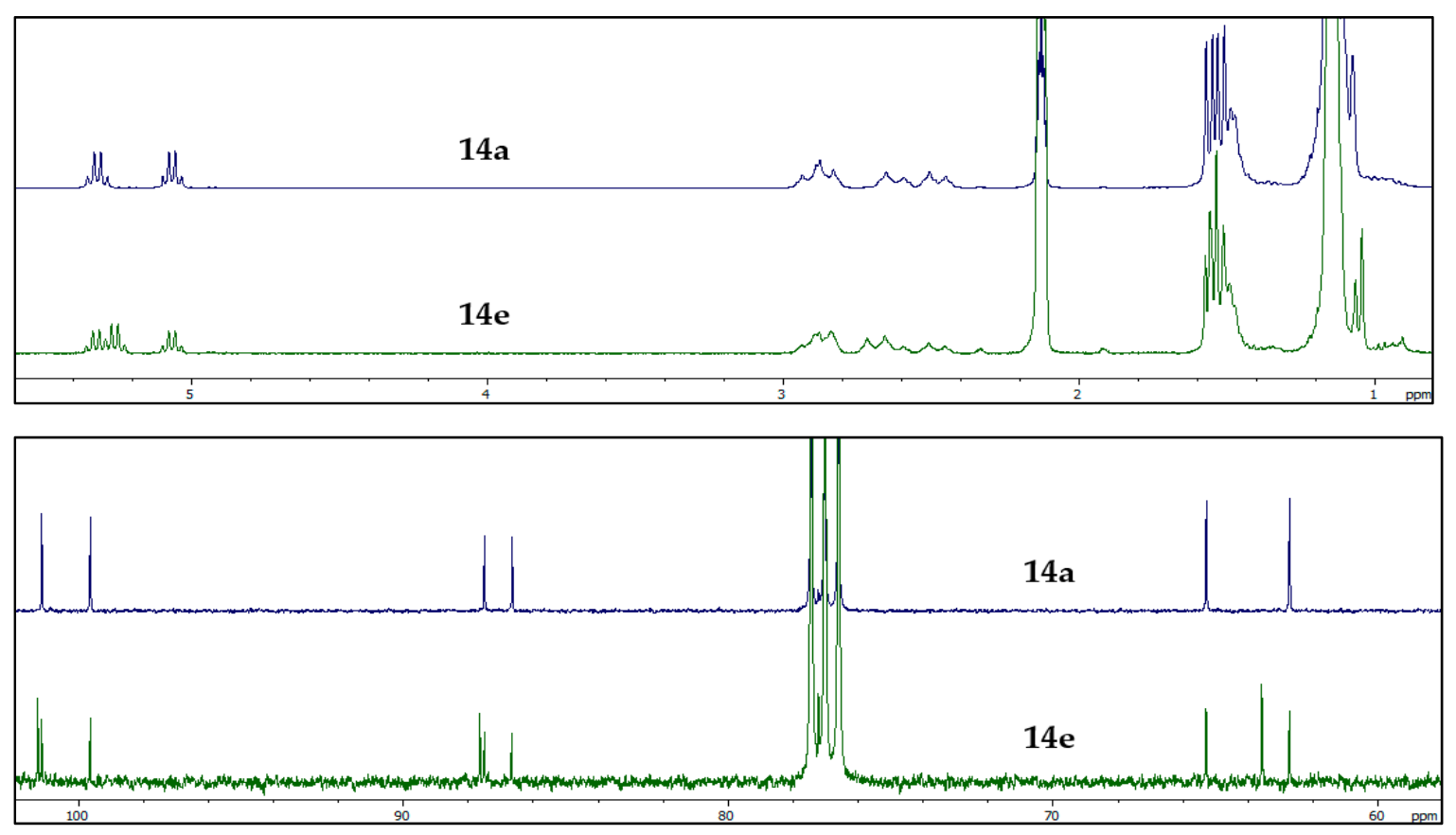

Figure 4. ${ }^{1} \mathrm{H}-\mathrm{NMR}$ spectrum of 14a and 14e in d8-toluene (top), and a zoom of the ${ }^{13} \mathrm{C}-\mathrm{NMR}$ spectrum of compounds 14a, and 14e in $\mathrm{CDCl}_{3}$ (bottom).

The quartet signal for the symmetric diastereo-isomer rendered an integral of $1.3 \mathrm{H}$ compared to $2 \mathrm{H}$ for $\mathbf{1 4} \mathbf{a}+\mathbf{1 4} \mathbf{a}^{\prime}$, which is significantly higher than the statistically expected integral of $1.0 \mathrm{H}$. Since all synthesized complexes $\mathbf{1 4 a - e}$ were found stable in air at room temperature over the course of several months, as well as during column chromatography over silica, this unusual diastereomeric product distribution is not likely a result from decomposition during these stages. However, partial decomposition during the synthetic reaction cannot be excluded, as incomplete mass balances of the iron complexes but no unreacted pre-ligand were obtained.

Alternatively, we propose the possibility that one of the symmetric diastereomers, supposedly $\mathbf{1 4 g}$, is sterically constrained to such an extent that ring closure of the alkynes cannot be achieved. Steric restrictions of such kind have been reported for the formation of a similar cyclopentadienone ruthenium complex as well [71]. In the case of $\mathbf{1 4} \mathbf{g}$ the bulky silyl groups are oriented towards the iron core (deduced from its DFT structure, vide infra) inhibiting ring closure. However, rearrangement of the alkynes onto the iron by dissociation, displacement, and re-coordination of one the alkyne moieties may lead to the formation of $\mathbf{1 4 f}$ in extra quantities (Scheme 5), as observed in NMR. 


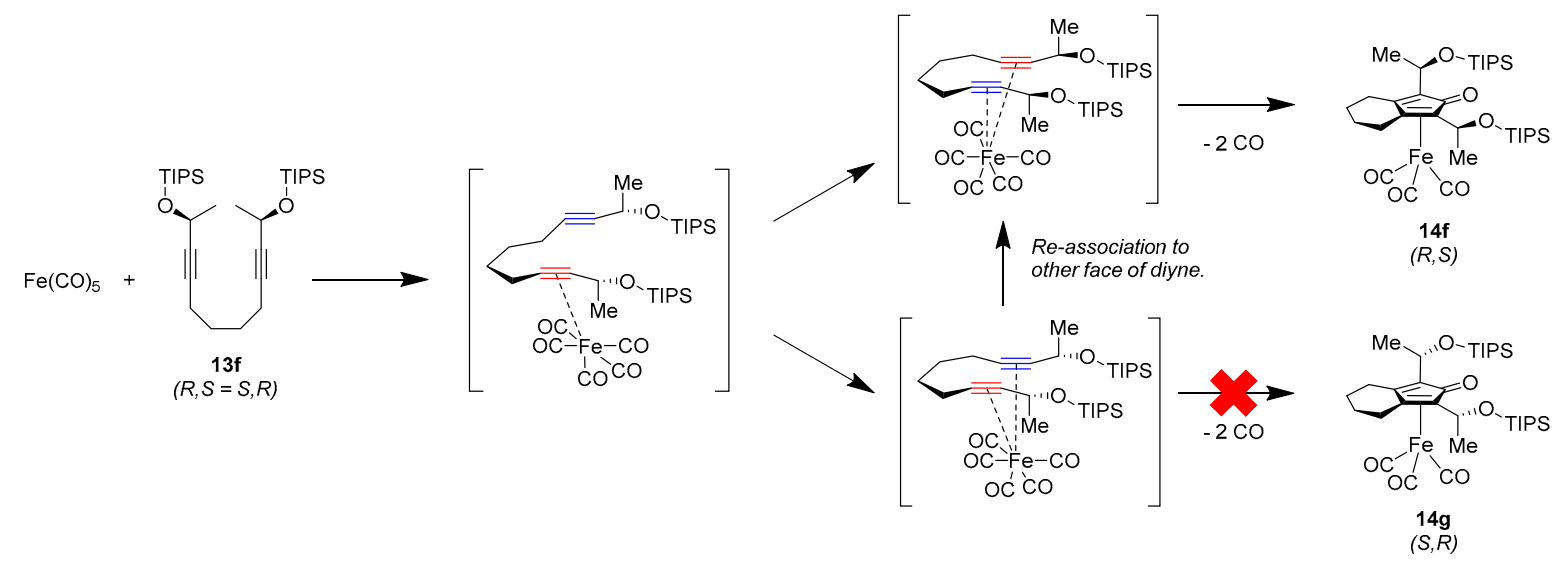

Scheme 5. Proposed complexation mechanism of mesomeric pre-ligand $\mathbf{1 3 f}$ with $\mathrm{Fe}(\mathrm{CO})_{5}$, yielding complex $14 \mathrm{f}$ only. Herein, formation of complex $14 \mathrm{~g}$ is excluded by steric aspects, and rearrangement of the coordinated alkyne moieties of intermediate species leads to $14 \mathrm{f}$ as well.

Another important implication is that potential racemization during any stage of the total synthesis would result in elimination of optical rotation, and the occurrence of more than one set of signals in NMR spectroscopy, as partial racemization of 14a into 14f cannot be excluded in this scenario. This is fortunately not the case for $\mathbf{1 4 a}-\mathbf{d}$, which evidences preservation of chiral information through their total synthesis, thus rendering these complexes enantio-pure.

\subsection{Computational Structure Assessment of the Novel Catalyst Design}

In order to assess the spatial conformation of complexes 14a-e a series of computational structure optimizations were conducted in lieu of a crystal structure determination, since the acquisition of suitable crystals of $\mathbf{1 4 a - d}$ proved very difficult. These calculations were conducted on DFT level using they hybrid B3LYP function [72,73], and the LANL2DZ core potential [74,75] was applied on all atoms.

The optimized structure of 14a exhibits the typical "piano-stool" complex, featuring $\eta_{4}$-coordination of the cyclopentadienone ligand onto iron, as expected (Figure 5, left). The enantio-pure 2,5-substituents are rotated in different dihedral angles, in which the bulky TIPS-groups are directed away from the core of the molecule, and the least sterically demanding methine hydrogens point towards the backbone of the ligand. As such, one TIPS group is oriented endo with respect to the iron, while the other is oriented exo, establishing the visibly asymmetric nature of the complex.

Assessment of the symmetric $\mathbf{1 4 f}$ and $\mathbf{1 4 g}$ diastereo-isomers reveals a conformational change regarding the TIPS groups, as they are oriented exo-exo, and endo-endo, respectively. These conformations bear different degrees of steric clashing, as the difference in Gibbs free energy $(\Delta \mathrm{G})$ between $\mathbf{1 4 f}$ and $\mathbf{1 4} \mathrm{g}$ is $5.29 \mathrm{kcal} \cdot \mathrm{mol}^{-1}$, and plausibly induces the formation of $14 \mathrm{f}$ only from the mesomeric diastereo-isomer of $\mathbf{1 3 e}$.

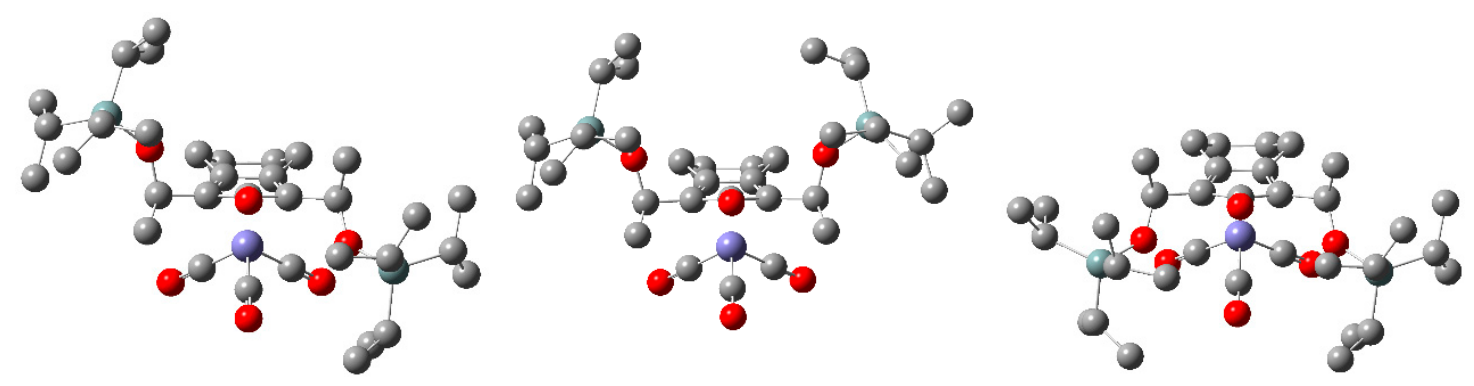

Figure 5. Optimized structures of complexes 14a (left), 14f, (middle), and 14g (right)—which are each other's diastereo-isomers-derived from DFT calculations. Hydrogens are omitted for clarity. 


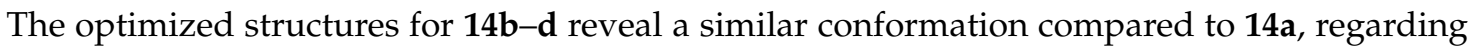
the orientation of the 2,5-substituents (Figure 6). Since the 2,5-substituents do possess some degree of rotational freedom, which is assumed different for each complex, we defined the corresponding dihedral angles $\theta$ and $\varphi$ for comparative reasons, as indicated in Figure 7.
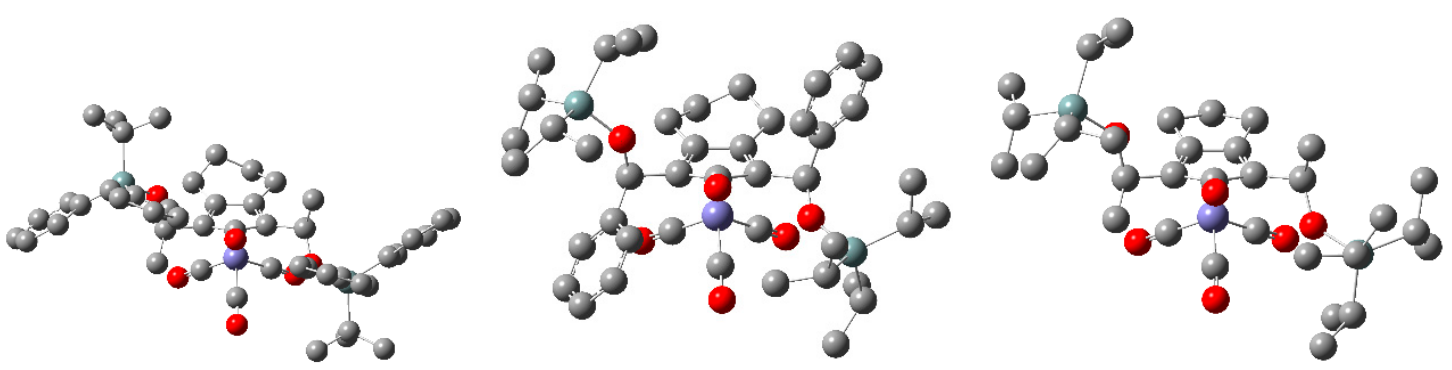

Figure 6. Optimized structures of complexes $14 b$ (left), 14c', (middle), and 14d (right) derived from DFT calculations. Hydrogens are omitted for clarity. The $S, S$-enantiomer of $14 \mathrm{c}$ was chosen to be calculated for comparative reasons.
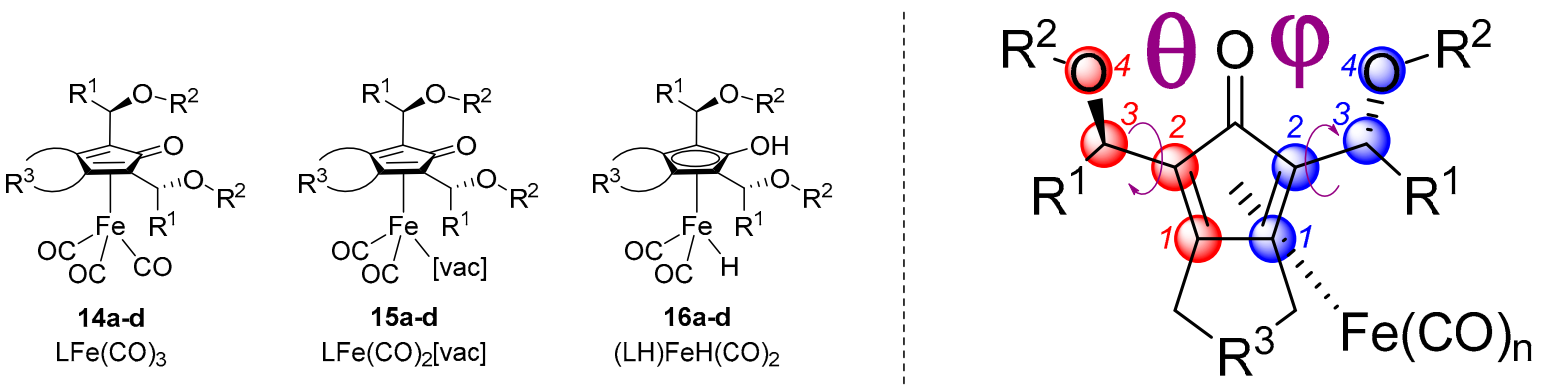

Figure 7. General structures for complexes 14, decarbonylated complexes 15, and active catalysts 16, in which angle $\theta$ describes the dihedral angle along labeled atoms 1-4 for the left-hand chiral substituent (as seen from top view), while $\varphi$ describes the dihedral angle for the right-hand chiral substituent.

In addition, the structures for the (cyclopentadienone)iron dicarbonyl (15a-d) and (hydroxycyclopentadiene)iron(II) dicarbonyl hydride (16a-d) were optimized as well, because they are more representative for the iron species within the catalytic cycle. Their values for $\theta$ and $\varphi$, and the absolute difference between $\theta$ and $\varphi$, are listed in Table 4 . From the overview it can be seen that for complexes $\mathbf{1 4}$ and $\mathbf{1 5}$ the endo-oriented substituent is affected the most upon structural variation, as indicated by $\theta$. Moreover, the rotations of $\theta$ and $\varphi$, and the increased angle of $|\theta-\varphi|$ for $\mathbf{1 4} \mathbf{c}^{\prime}$ and $\mathbf{1 5} \mathbf{c}^{\prime}$ deviate a lot from those of the other complexes. These observations indicate that $14 \mathrm{c}$ is significantly more constrained in rotational freedom than the other complexes, which is complementary to the deductions from NMR-analysis and enantioselectivity in catalysis (vide infra), concerning 14c.

Table 4. DFT-computed dihedral angles of the 2,5-substituents of the cyclopentadienone ligand.

\begin{tabular}{|c|c|c|c|c|c|c|c|c|c|}
\hline \multirow{2}{*}{ Entry } & \multicolumn{3}{|c|}{$\mathrm{LFe}(\mathrm{CO})_{3}(14)$} & \multicolumn{3}{|c|}{$\mathrm{LFe}(\mathrm{CO})_{2}[\mathrm{vac}](15)$} & \multicolumn{3}{|c|}{$(\mathrm{LH}) \mathrm{FeH}(\mathrm{CO})_{2}(16)$} \\
\hline & $\theta\left({ }^{\circ}\right)$ & $\varphi\left(^{\circ}\right)$ & $|\theta-\varphi|$ & $\theta\left({ }^{\circ}\right)$ & $\varphi\left(^{\circ}\right)$ & $|\theta-\varphi|$ & $\theta\left({ }^{\circ}\right)$ & $\varphi\left(^{\circ}\right)$ & $|\theta-\varphi|$ \\
\hline a & -133.2 & -76.6 & 56.6 & -135.6 & -80.7 & 54.9 & -168.7 & -80.8 & 87.9 \\
\hline b & -142.5 & -78.1 & 64.3 & -127.6 & -84.6 & 43.0 & -169.2 & -86.6 & 82.6 \\
\hline$c^{\prime}$ & -159.2 & -90.8 & 68.4 & -155.0 & -92.8 & 62.3 & -169.0 & -96.5 & 72.5 \\
\hline d & -132.5 & -77.5 & 54.9 & -129.8 & -80.0 & 49.8 & -170.1 & -82.4 & 87.7 \\
\hline $\mathbf{f}$ & 75.4 & -75.4 & 0.0 & \multirow{2}{*}{\multicolumn{3}{|c|}{$\mathrm{n} / \mathrm{a}$}} & \multirow{2}{*}{\multicolumn{3}{|c|}{$\mathrm{n} / \mathrm{a}$}} \\
\hline g & -135.2 & 134.9 & 0.3 & & & & & & \\
\hline
\end{tabular}

Therefore, DFT may serve as a preliminary tool for asymmetric Knölker complexes of this kind, to predict the enantioselectivity of one complex relative to another. However $\mathbf{1 6 a}-\mathbf{d}$ all exhibit a very 
similar rotation for $\theta$ of about $170^{\circ}$. This is attributed to hydrogen bonding between the hydroxy group and the oxygen of the left-hand chiral substituent, and may qualify structures $\mathbf{1 6 a -} \mathbf{d}$ unsuitable to base predictions upon.

\subsection{Performance of the Catalysts in Asymmetric Hydrogenation}

To probe the catalytic abilities of the synthesized complexes, the reduction of the representative substrate acetophenone was targeted. Initial experimentation conducted using the base case complex 14a in transfer hydrogenation with isopropyl alcohol (iPrOH) as hydrogen donor.

Since this reaction is subject to the Meerwein-Ponndorf-Verley (MPV) equilibrium, a substantial amount of excess $\mathrm{iPrOH}$ is required to drive the reaction forward [76]. Several amounts of $\mathrm{PrOH}$ were tested at $80^{\circ} \mathrm{C}$ (Table 5, Entries 1-4), which afforded modest conversions up to $24 \%$ for the most concentrated reaction mixture. To our delight, enantiomeric excesses (ee) of $40 \%$ in average favoring S-1-phenylethanol production were achieved, with slightly better enantioselectivities for more dilute systems. To find a suitable mitigation between conversion and enantioselectivity, 10 equivalents of $\mathrm{iPrOH}(10 \%$ substrate dilution) was selected for further experiments. Herein, addition of solvent without hydrogen-donative properties showed even further inhibition of conversion (Entries 5 and 6), while variation of the temperature indicated slightly better enantioselectivity at lower temperatures (Entries 7 and 8). Moreover, the advanced conversion upon higher temperature suggests that the MPV equilibrium was not reached within $24 \mathrm{~h}$, thus the reaction proceeds rather slowly.

Table 5. Asymmetric transfer hydrogenation of acetophenone catalyzed by complex 14a.

\begin{tabular}{|c|c|c|c|c|c|c|}
\hline Entry & Solvent & $\begin{array}{l}\text { equiv. } \\
i \text { PrOH }\end{array}$ & $\begin{array}{c}\text { Temperature } \\
\left({ }^{\circ} \mathrm{C}\right)\end{array}$ & $\begin{array}{c}\text { Conversion } \\
(\%)\end{array}$ & $\begin{array}{c}\mathrm{Ee} \\
(\%)\end{array}$ & $\begin{array}{l}\text { Enantiomeric } \\
\text { Configuration }\end{array}$ \\
\hline $1^{1}$ & none & 2.5 & 80 & 24 & 36 & $S$ \\
\hline $2^{1}$ & none & 10 & 80 & 15 & 41 & S \\
\hline $3^{1}$ & none & 17.5 & 80 & 9 & 42 & S \\
\hline $4^{1}$ & none & 25 & 80 & 8 & 42 & S \\
\hline $5^{2}$ & toluene & 10 & 80 & 7 & 39 & S \\
\hline $6^{2}$ & $\mathrm{tBuOH}$ & 10 & 80 & 3 & 42 & S \\
\hline 7 & none & 10 & 100 & 25 & 40 & S \\
\hline 8 & none & 10 & 60 & 11 & 45 & $S$ \\
\hline
\end{tabular}

1 With different amounts of iPrOH under solvent-free conditions, these concentrations vary accordingly. ${ }^{2}$ Delicate solvent volumes were added to afford the same concentration as in Entry 4.

In order to boost the reaction rates, and to eliminate the MPV equilibrium for allowing higher conversions, pressure hydrogenation using 50 bar $\mathrm{H}_{2}$ was conducted subsequently. Although near-complete conversion was readily achieved, the ee was decreased to $33 \%$ (Table 6, Entry 1). Variation of the solvent did not alter the enantioselectivity significantly, which appears a common factor for Knölker-type catalysts with the origin of asymmetry in the cyclopentadienone ligand [39], while the enantioselectivity for other types of catalysts is sometimes more susceptible to solvent effects [77]. However, significantly lower conversions were observed in methanol and 2-methyltetrahydrofuran (Entries 2-5).

Comparative screening of $14 a-\mathbf{e}$ at $80{ }^{\circ} \mathrm{C}$ rendered $99 \%$ conversion for all catalysts, while ee values varied from $21 \%$ to $41 \%$ ee in the order $\mathbf{1 4} \mathbf{c}>\mathbf{1 4 a}>\mathbf{1 4} \mathbf{b}>\mathbf{1 4 d}$ (Entries 6-8). Upon decreasing the temperature to $60{ }^{\circ} \mathrm{C}$, lower conversions are attained in the order of $14 \mathrm{~d}>14 \mathrm{a}>14 \mathrm{~b}>14 \mathrm{c}$. The corresponding ee values still showed the same trend with respect to the catalyst structures, but rendered significantly higher with a commendable peak of $62 \%$ for $14 c$. (Entries $9-12$ ). 
Table 6. Iron-catalyzed asymmetric pressure hydrogenation of acetophenone.

\begin{tabular}{|c|c|c|c|c|c|c|c|}
\hline Entry & Catalyst & Solvent & $\begin{array}{c}\text { Temperature } \\
\left({ }^{\circ} \mathrm{C}\right)\end{array}$ & $\begin{array}{l}\mathrm{H}_{2} \text { Pressure } \\
\text { (bar) }\end{array}$ & $\begin{array}{c}\text { Conversion } \\
(\%)\end{array}$ & $\begin{array}{l}\mathrm{Ee} \\
(\%)\end{array}$ & $\begin{array}{l}\text { Enantiomeric } \\
\text { Configuration }\end{array}$ \\
\hline 1 & $14 a$ & $\mathrm{iPrOH}$ & 80 & 50 & 99 & 33 & $S$ \\
\hline 2 & $14 a$ & $\mathrm{MeOH}$ & 80 & 50 & 5 & 30 & $S$ \\
\hline 3 & $14 a$ & $\mathrm{EtOH}$ & 80 & 50 & 99 & 33 & $S$ \\
\hline 4 & $14 a$ & toluene & 80 & 50 & 99 & 33 & $S$ \\
\hline 5 & $14 a$ & 2-MeTHF & 80 & 50 & 65 & 30 & $S$ \\
\hline 6 & $14 b$ & iPrOH & 80 & 50 & 99 & 21 & $S$ \\
\hline 7 & $14 \mathrm{c}$ & $\mathrm{iPrOH}$ & 80 & 50 & 99 & 41 & $R$ \\
\hline 8 & 14d & $\mathrm{iPrOH}$ & 80 & 50 & 99 & 21 & $S$ \\
\hline 9 & $14 \mathrm{e}$ & $\mathrm{iPrOH}$ & 80 & 50 & 99 & 0 & - \\
\hline 10 & $14 a$ & $\mathrm{iPrOH}$ & 60 & 50 & 74 & 40 & $S$ \\
\hline 11 & $14 b$ & $\mathrm{iPrOH}$ & 60 & 50 & 29 & 36 & $S$ \\
\hline 12 & $14 c$ & $\mathrm{iPrOH}$ & 60 & 50 & 14 & 62 & $R$ \\
\hline 13 & $14 d$ & $\mathrm{iPrOH}$ & 60 & 50 & 97 & 34 & $S$ \\
\hline $14^{1}$ & $14 a$ & $\mathrm{iPrOH}$ & 60 & 1 & 45 & 44 & $S$ \\
\hline $15^{1}$ & $14 a$ & $\mathrm{iPrOH}$ & 22 & 1 & 4 & 60 & $S$ \\
\hline
\end{tabular}

${ }^{1}$ The reaction was carried out in a Schlenk flask, equipped with a $\mathrm{H}_{2}$-filled balloon.

Moreover, the outcome of these catalyst-screening experiments suggest few structural trends: (1) an increased bulkiness of the asymmetric 2,5-substituents seems to enhance enantioselectivity, but at the cost of conversion, notably for 14c; (2) alteration of the ligand's backbone (i.e., $R^{3}$ ) again proves to be a more dominating factor than expected, as seen for 14d versus 14a. Furthermore, balloon experiments indicate that even milder conditions (e.g., $\mathrm{H}_{2}$ pressure, temperature) can already achieve a decent mitigation between conversion and ee (Entries 14-15).

With the influences of the investigated reaction conditions upon the yield and enantioselectivity for acetophenone hydrogenation using 14a-d now known, the most representative circumstance was selected to assess the catalytic performance for hydrogenation of different substrates. Several substituted acetophenone derivatives with varying electronic properties were screened (Table 7, Entries 1-5), as well as differently substituted ketones (Entries 6-9), and bio-derived methyl levulinate (Entry 10).

Decent to complete conversions were obtained using catalyst 14a, and enantio-selectivity favoring the $S$-product was always observed. Compared to the acetophenone hydrogenations, lower ee values were generally observed for the substituted analogues of this substrate, however, hydrogenation of 2,6-dihydroxyacetophenone and propiophenone rendered $47 \%$ ee. Low enantio-selectivity was observed towards non-aromatic substrates such as tert-butyl methyl ketone and methyl levulinate. Some substrates were subjected to catalysts $14 \mathrm{c}$ and $\mathbf{1 4 d}$ additionally. These examples followed a general trend, that $\mathbf{1 4} \mathrm{c}$ is a more selective but less active catalyst, and $\mathbf{1 4 d} \mathbf{d}$ is slightly less selective than 14a. Herein, the 14c-catalyzed hydrogenation of propiophenone yielded the highest enantioselectivity obtained in this work, rendering $70 \%$ ee. 
Table 7. Substrate scope for the iron-catalyzed asymmetric pressure hydrogenation.

\begin{tabular}{|c|c|c|c|c|c|}
\hline Entry & Substrate & Catalyst & Conversion (\%) & $\operatorname{Ee}(\%)$ & Enantiomeric Configuration \\
\hline 1 & & $14 a$ & 99 & 29 & $S$ \\
\hline 2 & & $14 a$ & 66 & 26 & $S$ \\
\hline 3 & & $14 a$ & 97 & 29 & $S$ \\
\hline 4 & & $\begin{array}{l}14 a \\
14 c \\
14 d\end{array}$ & $\begin{array}{l}97 \\
93 \\
72\end{array}$ & $\begin{array}{l}38 \\
56 \\
34\end{array}$ & $\begin{array}{l}S \\
R \\
S\end{array}$ \\
\hline 5 & & $14 a$ & 99 & 47 & $S$ \\
\hline 6 & & $\begin{array}{l}14 a \\
14 c \\
14 d\end{array}$ & $\begin{array}{l}69 \\
32 \\
95\end{array}$ & $\begin{array}{c}26 \\
63 \\
23\end{array}$ & $\begin{array}{l}S \\
R \\
S\end{array}$ \\
\hline 7 & & $\begin{array}{l}14 a \\
14 c\end{array}$ & $\begin{array}{l}100 \\
41\end{array}$ & $\begin{array}{l}14 \\
28\end{array}$ & $\begin{array}{l}S \\
R\end{array}$ \\
\hline 8 & & $\begin{array}{l}14 a \\
14 c\end{array}$ & $\begin{array}{c}100 \\
2\end{array}$ & $\begin{array}{c}3 \\
22\end{array}$ & $\begin{array}{l}S \\
R\end{array}$ \\
\hline 9 & & $\begin{array}{l}14 a \\
14 c \\
14 d\end{array}$ & $\begin{array}{l}98 \\
53 \\
68\end{array}$ & $\begin{array}{l}47 \\
70 \\
38\end{array}$ & $\begin{array}{l}S \\
R \\
S\end{array}$ \\
\hline $10^{1}$ & & $\begin{array}{l}14 a \\
14 c\end{array}$ & $\begin{array}{l}50 \\
32\end{array}$ & $\begin{array}{l}1 \\
4\end{array}$ & $\begin{array}{l}S \\
R\end{array}$ \\
\hline
\end{tabular}

${ }^{1}$ The reaction temperature was $80^{\circ} \mathrm{C}$.

\section{Materials and Methods}

\subsection{General Statements}

(R)-but-3-yn-2-ol (99\% pure, >99.5\% ee); (R)-1-phenylprop-2-yn-1-ol (99\% pure, $>99.5 \%$ ee); ( rac)-but-3-yn-2-ol (99\% pure); triisopropylsilyl chloride (97\% pure); tert-butyldiphenylsilyl chloride (98\% pure); imidazole (99\% pure); n-butyllithium (1.6 M in hexanes); 1,4-diiodobutane (98\% pure); 1,3-diiodopropane (98\% pure); iron pentacarbonyl ( $99 \%$ pure); diiron nonacarbonyl (99\% pure); trimethylamine-N-oxide (99\% pure); acetophenone ( $\geq 99 \%$ pure) were purchased from Sigma Aldrich (St. Louis, MO, USA) verified by NMR (Bruker, Billerica, MA, USA) and chiral GC-fid (Hewlett Packard, Palo Alto, CA, USA), and used without further purification. Ketones in the substrate scope were obtained from miscellaneous sources. Dry DCM was purchased from Sigma Aldrich (St. Louis, MO, USA); dry THF and dry toluene were drawn from a SPS MBraun solvent dispenser (Garching, 
Germany), and were always verified to contain $<100$ ppm water by titration using a Mettler Toledo C30S Compact Karl Fischer Coulometer (Columbus, OH, USA). All other solvents were HPLC-grade pure, and were purchased from Biosolve (Valkenswaard, The Netherlands).

All organic reactions were performed in oven-dried glassware under a $\mathrm{N}_{2}$ atmosphere using Schlenk techniques. Complexation reactions were performed in pressure tubes equipped with a magnetic stirring bar and a crimp-cap septum, using a Biotage Initiator + microwave.

Thin layer chromatography was conducted using aluminum TLC plates, coated with $\mu \mathrm{m} 60$ mesh normal phase silica and fluorescent indicator F254. Column chromatography was conducted manually using glass columns and $80-200 \mu \mathrm{m}$ mesh silica.

NMR spectra were recorded on a Bruker AVANCE-300 Ultra Shield spectrometer (Billerica, MA, USA), $300 \mathrm{MHz}$ for ${ }^{1} \mathrm{H}-\mathrm{NMR}$ and $75 \mathrm{MHz}$ for ${ }^{13} \mathrm{C}-\mathrm{NMR}$ at $25{ }^{\circ} \mathrm{C}$. FT-IR were recorded on a Shimadzu Miracle 10 FT-IR spectrometer (Kyoto, Japan) in the range of $400-4000 \mathrm{~cm}^{-1}$. Mass spectrometry was conducted using a Bruker solariX XR FT-ICR-MS mass-spectrometer (Billerica, MA, USA) with an ultra-high resolution over $10^{5}$. The applied MS parameters in positive mode were as following. Capillary: $4.4 \mathrm{kV}$; end plate offset: $-800 \mathrm{~V}$; nebulizer: $1 \mathrm{bar}$, dry gas $4 \mathrm{~L} / \mathrm{min}$, dry temperature $200^{\circ} \mathrm{C}$; mass range: $50-1000 \mathrm{Da}$. Samples were prepared by dissolving the compounds in $\mathrm{CH}_{2} \mathrm{Cl}_{2}-\mathrm{CH}_{3} \mathrm{CN}-\mathrm{CH}_{3} \mathrm{COOH}(49.95-49.95-0.1 \mathrm{vol} \%$ ).

Chiral organic products from the hydrogenation reactions were analyzed using a Hewlett Packard 5890 Series II gas chromatograph (Palo Alto, CA, USA), equipped with a flame-ionization detector, and a CP-Chirasil-Dex CB capillary column (length $=25 \mathrm{~m}$; internal diameter $=0.25 \mathrm{~mm}$; film thickness $=0.25 \mathrm{~mm}$ ). The heating program was $5 \mathrm{~min}$ at $40^{\circ} \mathrm{C}$, a ramp of $5^{\circ} \mathrm{C} / \mathrm{min}$ up to $200^{\circ} \mathrm{C}$ and a final $8 \mathrm{~min}$ at $200^{\circ} \mathrm{C}$. The (direction of) optical rotations of synthetic products and hydrogenation reaction mixtures were measured using a Bellingham + Stanley ADP410 polarimeter (Kent, UK), equipped with a $5.0 \mathrm{~cm}$ pathway sample chamber.

Computational calculations for all chemical geometries were performed by using the Gaussian software package (Version 09, Gaussian Inc., Wallingford, CT, USA, 2015). Optimizations were performed at the level of DFT by means of the hybrid B3LYP [72,73] functional and the basis set LANL2DZ [74,75] was employed for all elements. All calculations were performed without freezing any atom. Frequency calculations were performed for all stationary points at the same level to identify the minima (zero imaginary frequencies) and transition states (TS, only one imaginary frequency) and to provide free energies at $298.15 \mathrm{~K}$ and $1 \mathrm{~atm}$.

\subsection{General Procedure for the Synthesis of Alkynic Silyl Ethers $12 a-c$}

In oven-dried glassware under a nitrogen atmosphere, alkynol 11 (12.4 mmol, $1.0 \mathrm{eq})$, and imidazole ( $25 \mathrm{mmol}, 2.0 \mathrm{eq}$ ) were dissolved together in $30 \mathrm{~mL}$ of dry DCM, and silyl chloride (14.5 mmol, $1.2 \mathrm{eq}$ ) was dissolved separately in $15 \mathrm{~mL}$ of dry DCM. The alkynol/imidazole solution was cooled to $0{ }^{\circ} \mathrm{C}$, and the silyl chloride solution was added dropwise under vigorous stirring, upon which the formation of imidazolyl chloride salt was observed quite readily. Nevertheless, the mixture was stirred overnight at room temperature to ensure complete conversion. For workup, $20 \mathrm{~mL}$ of demineralized water was added for quenching. The biphasic mixture was separated, and the aqueous layer was back-extracted using $3 \times 15 \mathrm{~mL}$ ethyl acetate. The combined organic phases were subsequently extracted using $3 \times 30 \mathrm{~mL}$ of a saturated aqueous $\mathrm{NH}_{4} \mathrm{Cl}$ solution and dried over $\mathrm{MgSO}_{4}$. Upon concentration, chromatography over a silica column $( \pm 30 \mathrm{~cm} \times 1 \mathrm{~cm})$ using pure hexane as eluent, and thorough rotary vaporization the pure product was obtained. Staining with $\mathrm{KMnO}_{4} /$ alkaline solution is required to visualize the product in TLC.

\subsection{General Procedure for the Synthesis of Pre-Ligands 13a-e}

NOTE: For a successful reproduction, it is essential to ensure absolutely dry conditions, and to apply the stoichiometry of reagents and the temperature programming exactly as described below! 
In oven-dried glassware under a nitrogen atmosphere, alkynic silyl ether $\mathbf{1 3}$ ( $6.0 \mathrm{mmol}, 4.0 \mathrm{eq})$ was dissolved in $20 \mathrm{~mL}$ of dry THF, and diiodo alkane (1.5 mmol, $1.0 \mathrm{eq})$ was dissolved separately in $10 \mathrm{~mL}$ of dry THF. The alkynic silyl ether solution was cooled to $-80^{\circ} \mathrm{C}$ using an isopropanol/liquid $\mathrm{N}_{2}$ bath, and a commercial solution of $n$-butyllithium $1.6 \mathrm{M}$ in hexanes $(9.1 \mathrm{~mL}, 5.7 \mathrm{mmol}, 3.8 \mathrm{eq})$ was added dropwise over a course of $10 \mathrm{~min}$. The reaction was kept at $-80^{\circ} \mathrm{C}$ for $60 \mathrm{~min}$ to achieve complete alkyne deprotonation. Then, the diiodo alkane solution was added dropwise at $-80{ }^{\circ} \mathrm{C}$ under inert conditions, and the resulting reaction mixture was slowly heated to $60^{\circ} \mathrm{C}$ subsequently, and allowed to react for $18 \mathrm{~h}$. For workup, the reaction mixture was quenched with $5 \mathrm{~mL}$ of a saturated aqueous $\mathrm{NH}_{4} \mathrm{Cl}$ solution and $10 \mathrm{~mL}$ ethyl acetate was added to promote better phase separation. The biphasic mixture was separated, and the aqueous layer was back-extracted with $5 \mathrm{~mL}$ ethyl acetate, and using $15 \mathrm{~mL}$ of a saturated aqueous $\mathrm{NH}_{4} \mathrm{Cl}$ solution and dried over $\mathrm{MgSO}_{4}$. The final organic layer was dried using $\mathrm{MgSO}_{4}$ and the solution was concentrated. The crude product was purified by chromatography over a silica column $( \pm 80 \mathrm{~cm} \times 2 \mathrm{~cm})$ using $0-3 \%$ (slow increment) ethyl acetate/hexane eluent. Rotary vaporization of the carefully selected chromatography fractions yielded the pure dialkyne product, and the excess of alkynic silyl ether $\mathbf{1 2}$ could also be recovered for recycling. Staining with $\mathrm{KMnO}_{4} /$ alkaline solution is required to visualize the product in TLC.

\subsection{General Procedure for the Synthesis of Iron Complexes $\mathbf{1 4 a - e}$}

CAUTION: This reaction builds up a significant pressure ( \pm 7 bar) of $\mathrm{CO}$ gas, and a very thorough consideration on how to handle and neutralize this pressurized lethal gas is essential to warrant safety! We used dedicated microwave equipment from Biotage ${ }^{\circledR}$, which firmly clamps the crimp-cap onto the vial, monitors the pressure in real-time, and has a steel-cage chamber equipped with a sponge to absorb any potential leakage or explosion. We neutralized the CO-pressurized vials via: (1) ensuring that the reaction mixture was cooled to room temperature; (2) applying a $10 \mathrm{~mL}$ syringe equipped with a Luer lock and a thin needle to release the CO pressure manually, while keeping all materials deep inside a well-ventilated fume hood. (Hold the syringe firmly with your thumb on the plunger, pierce the septum carefully with the needle and collect the CO gas in the syringe in a controlled manner. Then, withdraw the needle and release the $\mathrm{CO}$ gas from the syringe deep and high inside the fume hood (the septum from Biotage ${ }^{\circledR}$ will close and withstand the remaining pressure). Repeat the manual CO extractions with the syringe, until all pressure is released.); (3) Purging the headspace of the microwave vial via needles using a balloon of nitrogen inside a well-ventilated fume hood. Then finally, the crimp-cap can be safely removed from the vial.

A 30-mL glass pressure vial from with a stirring magnet was mounted inside a large Schlenk flask, and the system was purged under a nitrogen atmosphere. Under outflow of a nitrogen stream, dialkyne $6(1.2 \mathrm{mmol}, 1.0 \mathrm{eq})$ and $15 \mathrm{~mL}$ of dry toluene, and finally $\mathrm{Fe}(\mathrm{CO})_{5}(5 \mathrm{mmol}, 4-5 \mathrm{eq})$ were added into the pressure vial, and the vial was sealed using a dedicated crimp-cap septum. The mixture was reacted by microwave irradiation to a constant temperature of $140{ }^{\circ} \mathrm{C}$ for $18 \mathrm{~h}$, during which the formation of CO pressure was observed to build up to 10 bar over the course of 4-8 h. After cooling down to room temperature, the vial was still pressurized with 7 bar CO gas, which was very carefully released as described above in the red 'caution' section. The neutralized reaction mixture was passed through a Celite column $( \pm 30 \mathrm{~cm} \times 1 \mathrm{~cm})$ using $100 \mathrm{~mL}$ ethyl acetate to remove solid iron carbonyl particles, and resulting solution was pushed through a millipore filter subsequently to remove paramagnetic iron nanoparticles. After removal of the ethyl acetate by rotary vaporization, the concentrated crude product was purified by chromatography over a silica column $( \pm 50 \mathrm{~cm} \times 2 \mathrm{~cm})$ using $0-5 \%$ ethyl acetate/hexane eluent. Rotary vaporization of the product fractions yielded the pure Knölker-type iron complex. Visualization of the product in TLC is possible under UV-light, but also by staining with $\mathrm{KMnO}_{4} /$ alkaline solution. 


\subsection{General Procedure for Transfer-Hydrogenation}

In oven-dried Schlenk flasks under a nitrogen atmosphere, separate stock solutions of pre-catalyst 14a $(0.052 \mathrm{M}), \mathrm{Me}_{3} \mathrm{NO}(0.156 \mathrm{M})$, in degassed isopropanol were prepared. Generally, $20.0 \mu \mathrm{L}$ of these stock solutions, $117 \mu \mathrm{L}$ of acetophenone, aliquots of isopropanol, and optionally amounts of extra solvent were added into oven-dried 5-mL Schlenk flasks under a nitrogen atmosphere to obtain the ratios as described in Table 5. The reaction mixtures were heated in pre-heated oil baths at the desired temperature for $24 \mathrm{~h}$. Samples for GC-analysis were prepared by dissolving delicate aliquots of reaction mixture in $1.00 \mathrm{~mL}$ of a $0.1 \mathrm{vol} \%$ solution of hexadecane in DCM.

\subsection{General Procedure for Pressure-Hydrogenation}

Hydrogenation reactions were performed in 3-mL glass vials equipped with a magnetic stirring bar. First, solid reagents (i.e., catalyst $(0.010 \mathrm{mmol}), \mathrm{Me}_{3} \mathrm{NO}(0.03 \mathrm{mmol})$, and certain substrates $(1.00 \mathrm{mmol})$ ) were loaded. Each vial was then inserted in a Schenk flask and purged under $\mathrm{N}_{2}$ by applying three vacuum/ $\mathrm{N}_{2}$ cycles, and isopropanol $(1.00 \mathrm{~mL})$ and liquid substrates $(1.00 \mathrm{mmol})$. A disposable snap-cap was fitted on each vial under outflow of $\mathrm{N}_{2}$. Four of such reaction vials at a time were mounted inside a $5500 \mathrm{HP}$ compact $100 \mathrm{~mL}$ autoclave from Parr Instrument Company, and the snap-caps were pierced once with a thick needle to allow gas exchange. The reactor was sealed, purged with $5 \times 2.5$ bar $\mathrm{N}_{2}$ and $3 \times 10$ bar $\mathrm{H}_{2}$, and finally charged with 50 bar $\mathrm{H}_{2}$ pressure. Subsequently, the system was heated to the desired temperature using 'mode 1 ' (i.e., using $40 \%$ electric power) to avoid a temperature overshoot, and the reaction mixtures were magnetically stirred at $300 \mathrm{rpm}$ using a stirring plate placed underneath the autoclave. After $24 \mathrm{~h}$, the reactions were stopped by allowing the reactor to cool down below $40{ }^{\circ} \mathrm{C}$ within $15 \mathrm{~min}$, after which the reactor was purged with $3 \times 2.5 \mathrm{bar}$ $\mathrm{N}_{2}$ before opening.

Samples for GC-analysis were prepared by dissolving $50.0 \mu \mathrm{L}$ reaction mixture in $1.00 \mathrm{~mL}$ of a $0.1 \mathrm{vol} \%$ solution of hexadecane in DCM.

\section{Conclusions}

We have successfully synthesized a new series of asymmetric Knölker-type iron catalysts, which exhibit the centers of chirality at the front side of the catalyst near the catalytically active site. Amongst the four asymmetric complexes a structural alteration in each variable fragment of the cyclopentadienone ligand (i.e., $R^{1}, R^{2}$, and $R^{3}$ ) compared to base-case complex $14 a$ was made. NMR analysis was particularly useful to study the asymmetric nature of the complexes, and it could even be used as a tool to confirm preservation of enantio-purity throughout the total synthesis of the complexes. In addition, DFT calculations provided useful insights on the structural conformation of the chiral substituents on the ligand, and the role of the ligand's backbone herein.

All synthesized iron complexes exhibited catalytic activity in the pressure hydrogenation of ketones, while transfer hydrogenation was also established using 14a. Complexes 14a-d rendered ee values in the range of $21-62 \%$ for the hydrogenation of acetophenone, and $70 \%$ as highest ee in the substrate screening catalyzed by 14c, which ranks our structural design in the top three of enantioselective Knölker-type catalysts.

Future research will focus on extending the structural examples within the series of our catalyst design, aiming for a superior catalytic performance to make environmentally considerate iron more attractive in applied and industrial chemistry.

Supplementary Materials: The following are available online at http://www.mdpi.com/2073-4344/9/10/790/s1.

Author Contributions: Conceptualization, C.A.M.R.v.S.; methodology, C.A.M.R.v.S., L.M., K.C.C., D.H., and B.B.; software, C.A.M.R.v.S.; validation, C.A.M.R.v.S., B.B., and S.M.A.D.W.; formal analysis, C.A.M.R.v.S., L.M., K.C.C. and D.H.; investigation, C.A.M.R.v.S., L.M., and K.C.C.; resources, S.M.A.D.W.; data curation, C.A.M.R.v.S., L.M., K.C.C. and D.H.; writing-original draft preparation, C.A.M.R.v.S.; writing-review and editing, B.B. and S.M.A.D.W.; visualization, C.A.M.R.v.S.; supervision, S.M.A.D.W.; project administration, C.A.M.R.v.S., and S.M.A.D.W.; funding acquisition, S.M.A.D.W. 
Funding: This research and the APC were funded by the framework of the public-private knowledge institute of Chemelot InSciTe.

Acknowledgments: We would like to thank Maarten Honing for offering his mass spectrometry equipment for our use; Andrij Pich, Ayse Deniz, and Wenjing Xu for arranging the elemental analysis; and Gerard Verzijl for his inspirational support to the general catalyst structure. Special appreciation to Martien Brouwers, Gerard Verzijl, and Jeroen Welzen for the donation and installation of their GC-fid equipment.

Conflicts of Interest: The authors declare no conflict of interest.

\section{Appendix A}

\section{(R)-(but-3-yn-2-yloxy)triisopropylsilane (12a)}

Appearance: colorless liquid. Yield (isolated): $92.7 \% .{ }^{1} \mathrm{H}-\mathrm{NMR}(300 \mathrm{MHz}), 25{ }^{\circ} \mathrm{C}, \mathrm{CDCl}_{3}(7.26 \mathrm{ppm})$ : $\delta=4.60\left(\mathrm{qd}, J_{1}=6.5 \mathrm{~Hz}, J_{2}=2.0 \mathrm{~Hz}, 1 \mathrm{H}, \mathrm{CHO}\right), 2.37(\mathrm{~d}, J=2.0,1 \mathrm{H}, \mathrm{C} \equiv \mathrm{CH}), 1.46(\mathrm{~d}, J=6.5 \mathrm{~Hz}, 3 \mathrm{H}$, $\mathrm{Me}), 1.34-0.83\left(\mathrm{~m}, 6 \mathrm{H}, \mathrm{Si}\left(\mathrm{CHMe}_{2}\right)_{3}\right), 1.09\left(\mathrm{~d}, J=3.5 \mathrm{~Hz}, 36 \mathrm{H}, \mathrm{Si}\left(\mathrm{CHMe}_{2}\right)_{3}\right)$ ppm. ${ }^{13} \mathrm{C}-\mathrm{NMR}(75 \mathrm{MHz})$, $25^{\circ} \mathrm{C}, \mathrm{CDCl}_{3}$ (77.16 ppm): $\delta=86.80,71.18,58.94,25.72,18.11,18.09,12.30$ ppm. FT-IR: 629, 654, 679, 752, 835, 881, 918, 974, 991, 1014, 1059, 1101, 1121, 1250, 1313, 1337, 1370, 1384, 1464, 2866, 2891, 2943, $3312 \mathrm{~cm}^{-1} \cdot[\alpha]_{D}^{25}=+96.1(\mathrm{c}=2.44 \mathrm{in} \mathrm{DCM})$.

\section{(R)-(but-3-yn-2-yloxy)(tert-butyl)diphenylsilane (12b)}

Appearance: colorless liquid. Yield (isolated): 91.3\%. ${ }^{1} \mathrm{H}-\mathrm{NMR}(300 \mathrm{MHz}), 25{ }^{\circ} \mathrm{C}, \mathrm{CDCl}_{3}(7.26 \mathrm{ppm})$ : $\delta=7.91-7.65\left(\mathrm{~m}, 4 \mathrm{H}, \mathrm{C}_{6} \mathrm{H}_{5}\right), 7.53-7.37\left(\mathrm{~m}, 6 \mathrm{H}, \mathrm{C}_{6} \mathrm{H}_{5}\right), 4.52\left(\mathrm{qd}, J_{1}=6.5 \mathrm{~Hz}, J_{2}=2.0 \mathrm{~Hz}, 1 \mathrm{H}, \mathrm{CHO}\right), 2.37$ $(\mathrm{d}, J=2.1 \mathrm{~Hz}, 1 \mathrm{H}, \mathrm{C} \equiv \mathrm{CH}), 1.45(\mathrm{~d}, J=6.5 \mathrm{~Hz}, 3 \mathrm{H}, \mathrm{Me}), 1.15$ (s, 9H, tBu) ppm. ${ }^{13} \mathrm{C}-\mathrm{NMR}(75 \mathrm{MHz})$, $25{ }^{\circ} \mathrm{C}, \mathrm{CDCl}_{3}(77.16 \mathrm{ppm}): \delta=136.09,135.90,133.84,133.55,129.90,129.86,127.77,127.66,86.20,71.72$, 59.93, 27.00, 25.30, 19.33 ppm. FT-IR: 544, 611, 657, 700, 739, 762, 822, 841, 938, 974, 1057, 1098, 1427, $1471,2859,2889,2932,2959,3070,3306 \mathrm{~cm}^{-1} \cdot[\alpha]_{D}^{24}=+288.3(\mathrm{c}=2.23$ in DCM $)$.

\section{(R)- triisopropyl((1-phenylprop-2-yn-1-yl)oxy)silane (12c)}

Appearance $=$ viscous yellow liquid. Yield (isolated): 85.5\%. ${ }^{1} \mathrm{H}-\mathrm{NMR}(300 \mathrm{MHz}), 25{ }^{\circ} \mathrm{C}, \mathrm{CDCl}_{3}$ (7.26 ppm): $\delta=7.56\left(\mathrm{~d}, J=7.3,2 \mathrm{H}, \mathrm{C}_{6} \mathrm{H}_{5}\right), 7.48-7.29\left(\mathrm{~m}, 3 \mathrm{H}, \mathrm{C}_{6} \mathrm{H}_{5}\right), 5.62(\mathrm{~d}, J=2.0 \mathrm{~Hz}, 1 \mathrm{H}, \mathrm{CHO}), 2.58$ $(\mathrm{d}, J=2.2 \mathrm{~Hz}, 3 \mathrm{H}, \mathrm{Me}), 1.36-1.21(\mathrm{~m}, 2 \mathrm{H}), 1.22-1.10\left(\mathrm{~m}, 18 \mathrm{H}, \mathrm{Si}\left(\mathrm{CHMe}_{2}\right)_{3}\right)$ ppm. ${ }^{13} \mathrm{C}-\mathrm{NMR}(75 \mathrm{MHz})$, $25^{\circ} \mathrm{C}, \mathrm{CDCl}_{3}$ (77.16 ppm): $\delta=142.04,128.49,127.88,125.98,85.32,77 . \overline{58,77} .16,76.74,73.53,64.83,18.13$, 12.39 ppm. FT-IR: 575, 656, 681, 695, 733, 824, 834, 881, 918, 961, 997, 1015, 1028, 1063, 1092, 1192, 1265, $1317,1341,1366,1385,1462,1493,2866,2891,2943,3308 \mathrm{~cm}^{-1}$. $[\alpha]_{D}^{26}=-14.8(\mathrm{c}=2.16$ in DCM).

\section{(5R,14R)-3,3,16,16-tetraisopropyl-2,5,14,17-tetramethyl-4,15-dioxa-3,16-disilaoctadeca-6,12-diyne (13a)}

Appearance: pale yellow liquid. Yield (isolated): $89.1 \% .{ }^{1} \mathrm{H}-\mathrm{NMR}(300 \mathrm{MHz}), 25^{\circ} \mathrm{C}, \mathrm{CDCl}_{3}(7.26 \mathrm{ppm})$ : $\delta=4.57(\mathrm{q}, J=6.4 \mathrm{~Hz}, 2 \mathrm{H}, \mathrm{CHO}), 2.19\left(\mathrm{~m}, 4 \mathrm{H}, \mathrm{C} \equiv \mathrm{C}-\mathrm{CH}_{2}\right), 1.58\left(\mathrm{~m}, 4 \mathrm{H}, \mathrm{CH}_{2}\right), 1.41(\mathrm{~d}, J=6.4 \mathrm{~Hz}, 6 \mathrm{H}$, $\mathrm{Me}), 1.22-0.93\left(\mathrm{~m}, 6 \mathrm{H}, \mathrm{Si}\left(\mathrm{CHCH}_{3}\right)_{3}\right), 1.08\left(\mathrm{~d}, J=3.6 \mathrm{~Hz}, 36 \mathrm{H}, \mathrm{Si}\left(\mathrm{CHCH}_{3}\right)_{3}\right) \mathrm{ppm} .{ }^{13} \mathrm{C}-\mathrm{NMR}(75 \mathrm{MHz})$, $25^{\circ} \mathrm{C}, \mathrm{CDCl}_{3}$ (77.16 ppm): $\delta=83.48,83.08,77.58,77.36,77.16,76.74, \overline{59} .25,27.81,26.11,18.35,18.15$, 18.13, 12.35 ppm. FT-IR: 666, 677, 756, 881, 920, 949, 976, 1013, 1030, 1069, 1099, 1159, 1248, 1316, 1335, $1368,1383,1462,2236,2864,2892,2941 \mathrm{~cm}^{-1}$. ESI-MS (in $\mathrm{CH}_{2} \mathrm{Cl}_{2} / \mathrm{CH}_{3} \mathrm{CN} 1: 1 \mathrm{v} / \mathrm{v}$ with $\mathrm{CH}_{3} \mathrm{COOH}$ for $\left.\mathrm{M}=\mathrm{C}_{30} \mathrm{H}_{58} \mathrm{Si}_{2} \mathrm{O}_{2}\right): m / z=529.38515\left\{[\mathrm{M}+\mathrm{Na}]^{+}\right.$, calcd 693.356006. $[\alpha]_{D}^{22}=+122.6(\mathrm{c}=2.01$ in DCM $)$.

\section{(5R,14R)-2,2,5,14,17,17-hexamethyl-3,3,16,16-tetraphenyl-4,15-dioxa-3,16-disilaoctadeca-6,12-diyne (13b)}

Appearance: viscous colorless liquid. Yield (isolated): $38.7 \% .{ }^{1} \mathrm{H}-\mathrm{NMR}(300 \mathrm{MHz}), 25{ }^{\circ} \mathrm{C}, \mathrm{CDCl}_{3}$ $(7.26 \mathrm{ppm}): \delta=7.73\left(\mathrm{dd}, J_{1}=20.6 \mathrm{~Hz}, J_{2}=6.1 \mathrm{~Hz}, 8 \mathrm{H}, \mathrm{C}_{6} \mathrm{H}_{5}\right), 7.37\left(\mathrm{~d}, J=7.4 \mathrm{~Hz}, 12 \mathrm{H}, \mathrm{C}_{6} \mathrm{H}_{5}\right), 4.47$ $(\mathrm{q}, J=6.3 \mathrm{~Hz}, 2 \mathrm{H}, \mathrm{CHO}), 2.06\left(\mathrm{~m}, 4 \mathrm{H}, \mathrm{C} \equiv \mathrm{C}-\mathrm{CH}_{2}\right), 1.40\left(\mathrm{~m}, 4 \mathrm{H}, \mathrm{CH}_{2}\right), 1.38(\mathrm{~d}, J=6.4 \mathrm{~Hz}, 6 \mathrm{H}, \mathrm{Me})$, $1.07(\mathrm{~s}, 18 \mathrm{H}, t \mathrm{Bu}) \mathrm{ppm} .{ }^{13} \mathrm{C}-\mathrm{NMR}(75 \mathrm{MHz}), 25^{\circ} \mathrm{C}, \mathrm{CDCl}_{3}(77.16 \mathrm{ppm}): \delta=136.10,135.91,134.14$, 134.10, 129.74, 129.63, 127.66, 127.50, 83.88, 83.00, 60.31, 27.61, 27.02, 25.69, 19.33, 18.29 ppm. FT-IR: $611,698,738,822,951,974,998,1028,1080,1098,1161,1341,1368,1390,1427,1472,1589,2857,2891$, 
2930, $3070 \mathrm{~cm}^{-1}$. ESI-MS (in $\mathrm{CH}_{2} \mathrm{Cl}_{2} / \mathrm{CH}_{3} \mathrm{CN} \mathrm{1:1} \mathrm{v/v} \mathrm{with} \mathrm{CH}_{3} \mathrm{COOH}$ for $\mathrm{M}=\mathrm{C}_{44} \mathrm{H}_{54} \mathrm{Si}_{2} \mathrm{O}_{2}$ ): $\mathrm{m} / \mathrm{z}=$ $693.35186\left\{[\mathrm{M}+\mathrm{Na}]^{+}\right.$, calcd 529.387306 $\} .[\alpha]_{D}^{26}=+364.1(\mathrm{c}=2.17$ in DCM).

(5R,14R)-3,3,16,16-tetraisopropyl-2,17-dimethyl-5,14-diphenyl-4,15-dioxa-3,16-disilaoctadeca-6,12-diyne (13c)

Appearance: viscous orange liquid. Yield (isolated): 60.8\%. ${ }^{1} \mathrm{H}-\mathrm{NMR}(300 \mathrm{MHz}), 25{ }^{\circ} \mathrm{C}, \mathrm{CDCl}_{3}$ (7.26 ppm): $\delta=7.52-7.17\left(\mathrm{~m}, 4 \mathrm{H}, \mathrm{C}_{6} \mathrm{H}_{5}\right), 7.14\left(\mathrm{~m}, J=6.8,6 \mathrm{H}, \mathrm{C}_{6} \mathrm{H}_{5}\right), 5.46(\mathrm{~s}, 2 \mathrm{H}, \mathrm{CHO}), 2.10(\mathrm{~b}, 4 \mathrm{H}$, $\left.\mathrm{C} \equiv \mathrm{C}-\mathrm{CH}_{2}\right), 1.48\left(\mathrm{~b}, 4 \mathrm{H}, \mathrm{CH}_{2}\right), 1.08(\mathrm{~m}, 6 \mathrm{H}), 1.00\left(\mathrm{dd}, J_{1}=12.3, J_{2}=6.0,36 \mathrm{H}\right) \mathrm{ppm} .{ }^{13} \mathrm{C}-\mathrm{NMR}(75$ $\mathrm{MHz}), 2{ }^{\circ} \mathrm{C}, \mathrm{CDCl}_{3}$ (77.16 ppm): $\delta=143.00,128.26,127.44,125.94,85.47,82.10,65.07,27.67,18.44$, 18.17, 12.44 ppm. FT-IR: 581, 629, 659, 681, 694, 721, 820, 881, 918, 996, 1013, 1026, 1057, 1083, 1134, $1194,1273,1329,1367,1383,1462,1492,2864,2891,2941 \mathrm{~cm}^{-1}$. ESI-MS (in $\mathrm{CH}_{2} \mathrm{Cl}_{2} / \mathrm{CH}_{3} \mathrm{CN}$ 1:1 v/v with $\mathrm{CH}_{3} \mathrm{COOH}$ for $\left.\mathrm{M}=\mathrm{C}_{44} \mathrm{H}_{54} \mathrm{Si}_{2} \mathrm{O}_{2}\right): \mathrm{m} / z=653.41845\left\{[\mathrm{M}+\mathrm{Na}]^{+}\right.$, calcd 653.418606\}; 669.41330 $\left\{\left[\mathrm{M}+\mathrm{K}^{+}\right.\right.$, calcd 669.392544\}. $[\alpha]_{D}^{26}=-37.0(\mathrm{c}=2.00$ in DCM $)$.

(5R,13R)-3,3,15,15-tetraisopropyl-2,5,13,16-tetramethyl-4,14-dioxa-3,15-disilaheptadeca-6,11-diyne (13d)

Appearance: pale yellow liquid. Yield (isolated): $70.3 \% .{ }^{1} \mathrm{H}-\mathrm{NMR}(300 \mathrm{MHz}), 2{ }^{\circ} \mathrm{C}, \mathrm{CDCl}_{3}(7.26 \mathrm{ppm})$ : $\delta=4.57(\mathrm{q}, J=6.4 \mathrm{~Hz}, 2 \mathrm{H}, \mathrm{CHO}), 2.28\left(\mathrm{td}, J_{1}=7.0 \mathrm{~Hz}, J_{2}=1.6 \mathrm{~Hz}, 4 \mathrm{H}, \mathrm{C} \equiv \mathrm{C}-\mathrm{CH}_{2}\right), 1.66(\mathrm{p}, J=7.1 \mathrm{~Hz}, 2 \mathrm{H}$, $\left.\left.\mathrm{CH}_{2}\right), 1.41(\mathrm{~d}, J=6.4 \mathrm{~Hz}, 6 \mathrm{H}, \mathrm{Me}), 1.22-0.93\left(\mathrm{~m}, 6 \mathrm{H}, \mathrm{Si}\left(\mathrm{CHMe}_{2}\right)_{3}\right), 1.08\left(\mathrm{~d}, J=3.7 \mathrm{~Hz}, 36 \mathrm{H}, \mathrm{Si}\left(\mathrm{CHMe}_{2}\right)_{3}\right)\right)$ ppm. ${ }^{13} \mathrm{C}-\mathrm{NMR}(75 \mathrm{MHz}), 25{ }^{\circ} \mathrm{C}, \mathrm{CDCl}_{3}$ (77.16 ppm): $\delta=83.76,82.55,77.58,77.16,76.74,59.23,27.91$, 26.08, 18.15, 18.12, 12.35 ppm. FT-IR: 657, 679, 756, 881, 920, 952, 973, 996, 1014, 1028, 1069, 1099, 1157, $1248,1316,1337,1368,1383,1464,2866,2891,2941 \mathrm{~cm}^{-1} \cdot[\alpha]_{D}^{26}=+131.9(\mathrm{c}=2.28$ in DCM $)$.

\section{$\eta^{4}$-[1,3-bis((R)-1-((triisopropylsilyl)oxy)ethyl)-4,5,6,7-tetrahydro-2H-inden-2-one]iron tricarbonyl (14a)}

Appearance: yellow solid. Yield (isolated): $51.4 \% .{ }^{1} \mathrm{H}-\mathrm{NMR}(300 \mathrm{MHz}), 25{ }^{\circ} \mathrm{C}, \mathrm{CDCl}_{3}$ (7.26 ppm): $\delta=4.99\left(\mathrm{dq}, J_{1}=66.3 \mathrm{~Hz}, J_{2}=6.4 \mathrm{~Hz}, 2 \mathrm{H}, \mathrm{CHO}\right), 3.01-2.42\left(\mathrm{~m}, 4 \mathrm{H},\left(\mathrm{CH}_{2}\right)_{2}\right), 1.80\left(\mathrm{~b}, 4 \mathrm{H}, \mathrm{Cp}-\mathrm{CH}_{2}\right)$, $1.47(\mathrm{~d}, J=6.4 \mathrm{~Hz}, 6 \mathrm{H}, \mathrm{Me}), 1.19-0.93(\mathrm{~m}, 42 \mathrm{H}, \mathrm{TIPS}) \mathrm{ppm} .{ }^{1} \mathrm{H}-\mathrm{NMR}(300 \mathrm{MHz}), 2{ }^{\circ} \mathrm{C}$, toluene-d 8 (2.08 ppm): $\delta 5.14\left(\mathrm{dq}, J_{1}=75.3, J_{1}=6.5,2 \mathrm{H}, \mathrm{CHO}\right), 2.84-2.30\left(\mathrm{~m}, 4 \mathrm{H}, \mathrm{Cp}-\mathrm{CH}_{2}\right), 1.63-1.34(\mathrm{~m}, 4 \mathrm{H})$, $1.49\left(\mathrm{dd}, J_{1}=11.7, J_{2}=6.5,6 \mathrm{H}, \mathrm{Me}\right), 1.25-0.8(\mathrm{~m}, 42 \mathrm{H}, \mathrm{TIPS}) .{ }^{13} \mathrm{C}-\mathrm{NMR}(\overline{5 \mathrm{MHz}}), 25{ }^{\circ} \mathrm{C}, \mathrm{CDCl}_{3}$ (77.16 ppm): $\delta=209.20,169.47,101.26,99.75,87.60,86.79,65.40,62.82,26.92,23.46,23.08,22.90,22.37$, 22.24, 18.42, 18.29, 18.27, 17.84, 13.16, 12.56, 12.43 ppm. FT-IR: 575, 594, 628, 653, 678, 737, 756, 770, 820, $881,928,993,1012,1065,1130,1256,1387,1464,1630,1987,2000,2060,2864,2943 \mathrm{~cm}^{-1}$. ESI-MS (in $\mathrm{CH}_{2} \mathrm{Cl}_{2} / \mathrm{CH}_{3} \mathrm{CN} 1: 1 \mathrm{v} / \mathrm{v}$ with $\mathrm{CH}_{3} \mathrm{COOH}$ for $\left.\mathrm{M}=\mathrm{C}_{34} \mathrm{H}_{58} \mathrm{Si}_{2} \mathrm{O}_{6} \mathrm{Fe}\right): \mathrm{m} / \mathrm{z}=675.31648\left\{[\mathrm{M}+\mathrm{H}]^{+}\right.$, calcd 675.319960\}; 697.29835 \{[M + Na $]^{+}$, calcd 697.301905\}. $[\alpha]_{D}^{22}=+16.5(\mathrm{c}=2.06$ in DCM).

\section{$\eta^{4}$-[1,3-bis((R)-1-((tert-butyldiphenylsilyl)oxy)ethyl)-4,5,6,7-tetrahydro-2H-inden-2-one]iron tricarbonyl (14b)}

Appearance: yellow solid. Yield (isolated): $33.8 \% .{ }^{1} \mathrm{H}-\mathrm{NMR}(300 \mathrm{MHz}), 25{ }^{\circ} \mathrm{C}, \mathrm{CDCl}_{3}(7.26 \mathrm{ppm})$ : $\delta=7.88-7.62\left(\mathrm{~m}, 8 \mathrm{H}, \mathrm{C}_{6} \mathrm{H}_{5}\right), 7.52-7.28\left(\mathrm{~m}, 12 \mathrm{H}, \mathrm{C}_{6} \mathrm{H}_{5}\right), 4.81\left(\mathrm{dq}, J_{1}=85.7 \mathrm{~Hz}, J_{2}=6.4 \mathrm{~Hz}, 2 \mathrm{H}, \mathrm{CHO}\right)$, 2.90-2.35 (m, 4H, $\left.\left(\mathrm{CH}_{2}\right)_{2}\right), 1.74\left(\mathrm{~m}, 4 \mathrm{H}, \mathrm{Cp}-\mathrm{CH}_{2}\right), 1.32\left(\mathrm{dd}, J_{1}=6.4 \mathrm{~Hz}, J_{2}=3.1 \mathrm{~Hz}, 6 \mathrm{H}, \mathrm{Me}\right), 1.08$ $(\mathrm{d}, J=5.0 \mathrm{~Hz}, 18 \mathrm{H}, \mathrm{tBu}) \mathrm{ppm} .{ }^{13} \mathrm{C}-\mathrm{NMR}(75 \overline{\mathrm{MHz}}), 2{ }^{\circ} \mathrm{C}, \mathrm{CDCl}_{3}(77.16 \mathrm{ppm}): \delta=209.22,169.74$, 136.12 , 136.09, 135.92, 135.78, 134.92, 134.39, 134.34, 133.72, 133.34, 129.85, 129.81, 129.80, 129.65, 127.76, $127.73,127.61,101.11,100.12,87.20,85.74,77.58,77.16,76.74,65.98,64.68,27.22,27.20,26.68,26.34$, 23.54, 23.17, 22.50, 22.15, 22.02, 19.45, 19.36 ppm. FT-IR: 574, 594, 604, 628, 700, 739, 822, 927, 991, 1078, $1105,1186,1260,1371,1427,1472,1645,1983,2060,2361,2857,2930,2956,3046,3071 \mathrm{~cm}^{-1}$. ESI-MS (in $\mathrm{CH}_{2} \mathrm{Cl}_{2} / \mathrm{CH}_{3} \mathrm{CN} 1: 1 \mathrm{v} / \mathrm{v}$ with $\mathrm{CH}_{3} \mathrm{COOH}$ for $\left.\mathrm{M}=\mathrm{C}_{48} \mathrm{H}_{54} \mathrm{Si}_{2} \mathrm{O}_{6} \mathrm{Fe}\right): \mathrm{m} / \mathrm{z}=839.28749\left\{[\mathrm{M}+\mathrm{H}]^{+}\right.$, calcd 839.288660\}; $861.270605\left\{[\mathrm{M}+\mathrm{Na}]^{+}\right.$, calcd 861.26817\}. Elemental analysis for $\mathrm{C}_{48} \mathrm{H}_{54} \mathrm{Si}_{2} \mathrm{O}_{6} \mathrm{Fe}$ : calcd: $\mathrm{C}$ $68.72 \%, \mathrm{H} 6.49 \%$; found, C $68.32 \%, \mathrm{H} 6.352 \%$. $[\alpha]_{D}^{22}=+62.5$ (c = 2.59 in DCM). 


\section{$\eta^{4}$-[1,3-bis $((R)$-phenyl((triisopropylsilyl)oxy)methyl)-4,5,6,7-tetrahydro-2H-inden-2-one]iron tricarbonyl (14c)}

Appearance: orange solid. Yield (isolated): $18.2 \% .{ }^{1} \mathrm{H}-\mathrm{NMR}(300 \mathrm{MHz}), 25{ }^{\circ} \mathrm{C}, \mathrm{CDCl}_{3}(7.26 \mathrm{ppm})$ : $\delta=7.48\left(\mathrm{dd}, J_{1}=45.1 \mathrm{~Hz}, J_{2}=7.3 \mathrm{~Hz}, 4 \mathrm{H}, \mathrm{C}_{6} \mathrm{H}_{5}\right), 7.16\left(\mathrm{~m}, 6 \mathrm{H}, \mathrm{C}_{6} \mathrm{H}_{5}\right), 5.94(\mathrm{~d}, J=52.7 \mathrm{~Hz}, 2 \mathrm{H}, \mathrm{CHO})$, $2.84\left(\mathrm{dd}, J_{1}=53.3 \mathrm{~Hz}, J_{2}=17.0 \mathrm{~Hz}, 2 \mathrm{H}, \mathrm{Cp}-\mathrm{CH}_{2}\right), 2.51-2.20\left(\mathrm{~m}, 2 \mathrm{H}, \mathrm{Cp}-\mathrm{CH}_{2}\right), 1.76-1.42\left(\mathrm{~m}, 4 \mathrm{H},\left(\mathrm{CH}_{2}\right)_{2}\right)$, $1.05-0.66$ (m, 42H, TIPS) ppm. $\left.{ }^{13} \mathrm{C}-\mathrm{NMR} \overline{(75} \mathrm{MHz}\right), 25{ }^{\circ} \mathrm{C}, \mathrm{CDCl}_{3}(77.16 \mathrm{ppm}): \delta=208.11,168.62$, 145.90, 143.69, 127.95, 127.87, 127.48, 127.16, 126.50, 126.40, 100.88, 98.81, 89.38, 86.10, 77.58, 77.16, 76.74, 70.69, 67.72, 23.43, 22.05, 22.01, 21.95, 18.37, 18.28, 18.15, 17.96, 12.82, 12.20 ppm. FT-IR: 571, 598, 613, $647,704,731,752,806,833,881,918,972,1015,1055,1084,1104,1173,1260,1288,1366,1423,1452,1492$, $1,1630,1993,2062,2359,2866,2891,2943,3030,3062 \mathrm{~cm}^{-1}$. ESI-MS (in $\mathrm{CH}_{2} \mathrm{Cl}_{2} / \mathrm{CH}_{3} \mathrm{CN}$ 1:1 v/v with $\mathrm{CH}_{3} \mathrm{COOH}$ for $\left.\mathrm{M}=\mathrm{C}_{44} \mathrm{H}_{62} \mathrm{Si}_{2} \mathrm{O}_{6} \mathrm{Fe}\right): m / z=799.35063\left\{[\mathrm{M}+\mathrm{H}]^{+}\right.$, calcd 799.351260\}; $821.33173\{[\mathrm{M}+$ $\mathrm{Na}]^{+}$, calcd 821.333205\}. $[\alpha]_{D}^{26}=+107.5(\mathrm{c}=2.14$ in DCM).

\section{$\eta^{4}$-[1,3-bis((R)-1-((triisopropylsilyl)oxy)ethyl)-5,6-dihydropentalen-2(4H)-one]iron tricarbonyl (14d)}

Appearance: yellow solid. Yield (isolated): 51.9\%. ${ }^{1} \mathrm{H}-\mathrm{NMR}(300 \mathrm{MHz}), 2{ }^{\circ} \mathrm{C}, \mathrm{CDCl}_{3}(7.26 \mathrm{ppm})$ : $\delta=4.89\left(\mathrm{dq}, J_{1}=28.1 \mathrm{~Hz}, J_{2}=6.2 \mathrm{~Hz}, 2 \mathrm{H}, \mathrm{CHO}\right), 2.88-2.70\left(\mathrm{~m}, 2 \mathrm{H}, \mathrm{Cp}-\mathrm{CH}_{2}\right), 2.69-2.45\left(\mathrm{~m}, 2 \mathrm{H}, \mathrm{Cp}-\mathrm{CH}_{2}\right)$, 2.43-2.21 (m, 1H, CH $\left.\mathrm{CH}_{2}\right), 1.98-1.77\left(\mathrm{~m}, 1 \mathrm{H}, \mathrm{CH}_{2}\right), 1.47\left(\mathrm{dd}, J_{1}=18.8 \mathrm{~Hz}, J_{2}=6.2 \mathrm{~Hz}, 6 \mathrm{H}, \mathrm{Me}\right), 1.08(\mathrm{~m}, 42 \mathrm{H}$, TIPS) ppm. ${ }^{13} \mathrm{C}-\mathrm{NMR}(75 \mathrm{MHz}), 2{ }^{\circ} \mathrm{C}, \mathrm{CDCl}_{3}(77.16 \mathrm{ppm}): \delta=209.15,171.58,105.90,105.09,88.58$, $88.21,64.83,64.13,27.61,27.54,26.52,26.48,24.26,18.41,18.30,18.24,13.17,12.90$ ppm. FT-IR: 576, 590, $605,618,635,675,737,799,841,880,918,953,1000,1013,1030,1065,1094,1125,1169,1206,1258,1364$, $1384,1438,1464,1622,1996,2062,2864,2891,2941,2967 \mathrm{~cm}^{-1}$. ESI-MS (in $\mathrm{CH}_{2} \mathrm{Cl}_{2} / \mathrm{CH}_{3} \mathrm{CN}$ 1:1 v/v with $\mathrm{CH}_{3} \mathrm{COOH}$ for $\left.\mathrm{M}=\mathrm{C}_{33} \mathrm{H}_{56} \mathrm{Si}_{2} \mathrm{O}_{6} \mathrm{Fe}\right): m / z=661.30282\left\{[\mathrm{M}+\mathrm{H}]^{+}\right.$, calcd 661.304310\}; 683.28437 $\{[\mathrm{M}+$ $\mathrm{Na}]^{+}$, calcd 683.286255\}; $699.25943\left\{[\mathrm{M}+\mathrm{K}]^{+}\right.$, calcd 699.260193\}. Elemental analysis for $\mathrm{C}_{33} \mathrm{H}_{56} \mathrm{Si}_{2} \mathrm{O}_{6} \mathrm{Fe}$ : calcd: C 59.98\%, H 8.54\%; found: C 59.55\%, H 8.59\%. $[\alpha]_{D}^{26}=+8.4$ (c = 2.15 in DCM).

\section{$14 f$ (R,S-complex extrapolated from racemic mixture 14e; signals of 14a also present in spectrum)}

${ }^{1} \mathrm{H}-\mathrm{NMR}(300 \mathrm{MHz}), 25^{\circ} \mathrm{C}, \mathrm{CDCl}_{3}(7.26 \mathrm{ppm}): \delta=5,08$ (q, $\left.J=6.4 \mathrm{~Hz}, 2 \mathrm{H}, \mathrm{CHO}\right), 3.01-2.42(\mathrm{~m}, 4 \mathrm{H}$, $\left.\left(\mathrm{CH}_{2}\right)_{2}\right), 1.80\left(\mathrm{~b}, 4 \mathrm{H}, \mathrm{Cp}-\mathrm{CH}_{2}\right), 1.47(\mathrm{~d}, \mathrm{~J}=6.4 \mathrm{~Hz}, 6 \mathrm{H}, \mathrm{Me}), 1.19-0.93(\mathrm{~m}, 42 \mathrm{H}, \mathrm{TIPS}) \mathrm{ppm} .{ }^{1} \mathrm{H}-\mathrm{NMR}$ $(300 \mathrm{MHz}), 25^{\circ} \mathrm{C}$, toluene- $\overline{\mathrm{d} 8}(2.08 \mathrm{ppm}): \delta=5,21(\mathrm{q}, J=6.3 \mathrm{~Hz}, 2 \mathrm{H}, \mathrm{CHO}), 3.01-2.42\left(\mathrm{~m}, 4 \mathrm{H},\left(\mathrm{CH}_{2}\right)_{2}\right)$, 1.80 (b, 4H, Cp-CH $), 1.47$ (d, J = 6.4 Hz, 6H, Me), 1.19-0.93 (m, 42H, TIPS) ppm. ${ }^{13} \mathrm{C}-\mathrm{NMR}(75 \mathrm{MHz})$, $25{ }^{\circ} \mathrm{C}, \mathrm{CDCl}_{3}(77 . \overline{16} \mathrm{ppm}): \delta=209.35,169.58,146.87,101.39,87.76,63.69,34.66,27.65,23.47,22.33$, 12.75 ppm. $[\alpha]_{D}^{25}=0.00(\mathrm{c}=2.02$ in DCM).

\section{References}

1. Knowles, W.S. Asymmetric Hydrogenations (Nobel Lecture). Angew. Chem. Int. Ed. 2002, 41, 1998-2007. [CrossRef]

2. Noyori, R. Asymmetric Catalysis: Science and Opportunities (Nobel Lecture). Angew. Chem. Int. Ed. 2002, 41, 2008-2022. [CrossRef]

3. Knowles, W.S. Application of Organometallic Catalysis to the Commercial Production of L-DOPA. J. Chem. Ed. 1986, 63, 222-225. [CrossRef]

4. Enthaler, S.; Junge, K.; Beller, M. Sustainable Metal Catalysis with Iron: From Rust to a Rising Star? Angew. Chem. Int. Ed. 2008, 47, 3317-3321. [CrossRef] [PubMed]

5. Bauer, G.; Kirchner, K.A. Well-Defined Bifunctional Iron Catalysts for the Hydrogenation of Ketones: Iron, the New Ruthenium. Angew. Chem. Int. Ed. 2011, 50, 5798-5800. [CrossRef] [PubMed]

6. Darwish, M.; Wills, M. Asymmetric catalysis using iron complexes-'Ruthenium Lite'? Catal. Schi. Technol. 2012, 2, 243-255. [CrossRef]

7. Li, Y.; Yu, S.; Wu, X.; Xiao, J.; Shen, W.; Dong, Z.; Gao, J. Iron Catalyzed Asymmetric Hydrogenation of Ketones. J. Am. Chem. Soc. 2014, 136, 4031-4039. [CrossRef]

8. Sues, P.E.; Demmans, K.Z.; Morris, R.H. Rational development of iron catalysts for asymmetric transfer hydrogenation. Dalton Trans. 2014, 43, 7650-7667. [CrossRef] 
9. Obligacion, J.V.; Chirik, P.J. Earth-abundant transition metal catalysts for alkene hydrosilylation and hydroboration. Nat. Rev. Chem. 2018, 2, 15-34. [CrossRef]

10. Zell, T.; Milstein, D. Hydrogenation and Dehydrogenation Iron Pincer Catalysts Capable of Metal-Ligand Cooperation by Aromatization/Dearomatization. Acc. Chem. Res. 2015, 48, 1979-1994. [CrossRef]

11. Bauer, I.; Knölker, H.-J. Iron Catalysis in Organic Synthesis. Chem. Rev. 2015, 115, 3170-3387. [CrossRef] [PubMed]

12. Reppe, W.; Vetter, H. Carbonylierung VI. Synthesen mit Metallcarbonylwasserstoffen. Liebigs Ann. Chem. 1953, 582, 133-161. [CrossRef]

13. Quintard, A.; Rodriquez, J. Iron Cyclopentadienone Complexes: Discovery, Properties, and Catalytic Reactivity. Angew. Chem. Int. Ed. 2014, 53, 4044-4055. [CrossRef] [PubMed]

14. Knölker, H.-J.; Heber, J.; Mahler, C.H. Transition Metal-Diene Complexes in Organic Synthesis, Part 14. Regioselective Iron-Mediated [2 $+2+1]$ Cycloadditions of Alkynes and Carbon Monoxide: Synthesis of Substituted Cyclopentadienones. Synlett 1992, 12, 1002-1004. [CrossRef]

15. Knölker, H.-J.; Heber, J. Transition Metal-Diene Complexes in Organic Synthesis, Part 18. Iron-Mediated [2+ $2+1$ ] Cycloadditions of Diynes and Carbon Monoxide: Selective Demetalation Reactions. Synlett 1993, 12, 924-926. [CrossRef]

16. Knölker, H.-J.; Baum, E.; Klauss, R. Transition Metal-Diene Complexes in Organic Synthesis, Part 25. Cycloadditions of Annulated 2,5-Bis(trimethylsilyl)cyclopentadienones. Tetrahedron Lett. 1995, 36, 7647-7650. [CrossRef]

17. Knölker, H.-J.; Baum, E.; Goesmann, R.; Klauss, R. A Novel Method for the Demetalation of Tricarbonyliron-Diene Complexes by a Photolytically Induced Ligand Exchange Reaction with Acetonitrile. Angew. Chem. Int. Ed. 1999, 38, 702-705. [CrossRef]

18. Knölker, H.-J.; Goesmann, R.; Klauss, R. Demetalation of Tricarbonyl(cyclopentadienone)iron Complexes Initiated by a Ligand Exchange Reaction with $\mathrm{NaOH}-$ X-Ray Analysis of a Complex with Nearly Square-Planar Coordinated Sodium. Angew. Chem. Int. Ed. 1999, 38, 2064-2066. [CrossRef]

19. Knölker, H.-J.; Braier, A.; Bröcher, D.J.; Cämmerer, S.; Fröhner, W.; Gonser, P.; Hermann, H.; Herzberg, D.; Reddy, K.R.; Rohde, G. Recent applications of tricarbonyliron-diene complexes to organic synthesis. Pure Appl. Chem. 2001, 73, 1075-1086. [CrossRef]

20. Casey, C.P.; Guan, H. An Efficient and Chemoselective Iron Catalyst for the Hydrogenation of Ketones. J. Am. Chem. Soc. 2007, 129, 5816-5817. [CrossRef]

21. Casey, C.P.; Guan, H. Cyclopentadienone Iron Alcohol Complexes: Synthesis, Reactivity, and Implications for the Mechanism of Iron-Catalyzed Hydrogenation of Aldehydes. J. Am. Chem. Soc. 2009, 131, 2499-2507. [CrossRef] [PubMed]

22. von der Höh, A.; Berkessel, A. Insights into the Mechanism of Dihydrogen-Heterolysis at Cyclopentadienone Iron Complexes and Subsequent $C=X$ Hydrogenation. Chem CatChem 2011, 3, 861-867. [CrossRef]

23. Lu, X.; Zhang, Y.; Yun, P.; Zhang, M.; Li, T. The mechanism for the hydrogenation of ketones catalyzed by Knölker's iron-catalyst. Org. Biomol. Chem. 2013, 11, 5264-5277. [CrossRef] [PubMed]

24. Berkessel, A.; Reichau, S.; von der Höh, A.; Leconte, N.; Neudörfl, J.-M. Light-Induced Enantioselective Hydrogenation Using Chiral Derivatives of Casey's Iron-Cyclopentadienone Catalyst. Organometallics 2011, 30, 3880-3887. [CrossRef]

25. Hopewell, J.P.; Martins, J.E.D.; Johnson, T.C.; Godfrey, J.; Wills, M. Developing asymmetric iron and ruthenium-based cyclone complexes; complex factors influence the asymmetric induction in the transfer hydrogenation of ketones. Org. Biomol. Chem. 2012, 10, 134-145. [CrossRef] [PubMed]

26. Natte, K.; Li, W.; Zhou, S.; Neumann, H.; Wu, X.-F. Iron-catalyzed reduction of aromatic aldehydes with paraformaldehyde and $\mathrm{H}_{2} \mathrm{O}$ as the hydrogen source. Tetrahedron Lett. 2015, 56, 1118-1121. [CrossRef]

27. Coleman, M.G.; Brown, A.N.; Bolton, B.A.; Guan, H. Iron-Catalyzed Oppenauer-Type Oxidation of Alcohols. Adv. Synth. Catal. 2010, 352, 967-970. [CrossRef]

28. Pagnoux-Ozherelyeva, A.; Pannetier, N.; Mbaye, M.D.; Gaillard, S.; Renaud, J.-L. Knölker's Iron Complex: An Efficient in Situ Generated Catalyst for Reductive Amination of Alkyl Aldehydes and Amines. Angew. Chem. Int. Ed. 2012, 124, 5060-5064. [CrossRef]

29. Tlili, A.; Schrank, J.; Neumann, H.; Beller, M. Discrete Iron Complexes for the Selective Catalytic Reduction of Aromatic, Aliphatic, and $\alpha, \beta$-Unsaturated Aldehydes under Water-Gas Shift Conditions. Chem. Eur. J. 2012, 18, 15935-15939. [CrossRef] 
30. Rosas-Hernández, A.; Junge, H.; Beller, M.; Roemelt, M.; Francke, R. Cyclopentadienone iron complexes as efficient and selective catalysts for the electroreduction of $\mathrm{CO}_{2}$ to CO. Catal. Sci. Technol. 2017, 7, 459-465. [CrossRef]

31. Elangovan, S.; Sortais, J.-B.; Beller, M.; Darcel, C. Iron-Catalyzed $\alpha$-Alkylation of Ketones with Alcohols. Angew. Chem. Int. Ed. 2015, 54, 14483-14486. [CrossRef] [PubMed]

32. Sun, Y.-Y.; Wang, H.; Chen, N.-Y.; Lennox, A.J.J.; Friedrich, A.; Xia, L.-M.; Lochbrunner, S.; Junge, H.; Beller, M.; Zhou, S.; et al. Efficient Photocatalytic Water Reduction Using in Situ Generated Knölker's Iron Complexes. ChemCatChem 2016, 8, 2340-2344. [CrossRef]

33. Quintard, A.; Constantieux, T.; Rodriquez, J. An Iron/Amine-catalyzed Cascade Process for the Enantioselective Functionalization of Allylic Alcohols. Angew. Chem. 2013, 125, 13121-13125. [CrossRef]

34. Roudier, M.; Constantieux, T.; Quintard, A.; Rodriquez, J. Enantioselective Cascade Formal Reductive Insertion of Allylic Alcohols into the $\mathrm{C}(\mathrm{O})$-C Bond of 1,3-Diketones: Ready Access to Synthetically Valuable 3-Alkylpentanol Units. Org. Lett. 2014, 16, 2802-2805. [CrossRef] [PubMed]

35. Roudier, M.; Constantieux, T.; Quintard, A.; Rodriquez, J. Triple Iron/Copper/Iminium Activation for the Efficient Redox Neutral Catalytic Enantioselective Functionalization of Allylic Alcohols. ACS Catal. 2016, 6, 5236-5244. [CrossRef]

36. Quintard, A.; Rodriquez, J. A Step into an eco-Compatible Future: Iron- and Cobalt-catalyzed Borrowing Hydrogen Transformation. ChemSusChem 2016, 9, 28-30. [CrossRef]

37. Quintard, A.; Rodriquez, J. Catalytic enantioselective OFF $\leftrightarrow \mathrm{ON}$ activation processes initiated by hydrogen transfer: Concepts and challenges. Chem. Commun. 2016, 52, 10456-10473. [CrossRef]

38. Rodriquez, J.; Quintard, A. Discovery of Eco-compatible Synthetic Paths by a Multi-catalysis Approach. Chimia 2018, 72, 580-583. [CrossRef]

39. Piarulli, U.; Vailati Fachini, S.; Pignataro, L. Enantioselective Reductions Promoted by (Cyclopentadienone)iron Complexes. Chimia 2017, 71, 580-585. [CrossRef]

40. Yamamoto, Y.; Akagi, M.; Shimanuki, K.; Kuwahara, S.; Watanabe, M.; Harada, N. A general method for the synthesis of enantiopure aliphatic chain alcohols with established absolute configurations. Part 1. Application of the M $\alpha \mathrm{NP}$ acid method to acetylene alcohols. Tetrahedron Asym. 2010, 25, 1456-1465. [CrossRef]

41. Johnson, T.C.; Clarkson, G.J.; Wills, M. (Cyclopentadienone)iron Shvo Complexes: Synthesis and Application to Hydrogen Transfer Reactions. Organometallics 2011, 30, 1850-1868. [CrossRef]

42. Hodgkinson, R.; Del Grosso, A.; Clarkson, G.; Wills, M. Iron cyclopentadienone complexes derived from $\mathrm{C}_{2}$-symmetric bis-propargylic alcohols; preparation and application to catalysis. Dalton Trans. 2016, 45, 3992-4005. [CrossRef] [PubMed]

43. Del Grosso, A.; Chamberlain, A.E.; Clarkson, G.J.; Wills, M. Synthesis and applications to catalysis of novel cyclopentadienone iron tricarbonyl complexes. Dalton Trans. 2018, 47, 1451-1470. [CrossRef] [PubMed]

44. Gajewski, P.; Renom-Carrasco, M.; Vailati Facchini, S.; Pignataro, L.; Lefort, L.; de Vries, J.G.; Ferraccioli, R.; Forni, A.; Piarulli, U.; Gennari, C. Chiral (Cyclopentadienone)iron Complexes for the Catalytic Asymmetric Hydrogenation of Ketones. Eur. J. Org. Chem. 2015, 9, 1887-1893. [CrossRef]

45. Gajewski, P.; Renom-Carrasco, M.; Vailati Facchini, S.; Pignataro, L.; Lefort, L.; de Vries, J.G.; Ferraccioli, R.; Piarulli, U.; Gennari, C. Synthesis of (R)-BINOL-Derived (Cyclopentadienone)iron Complexes and Their Application in the Catalytic Asymmetric Hydrogenation of Ketones. Eur. J. Org. Chem. 2015, 25, 5526-5536. [CrossRef]

46. Cettolin, M.; Bai, X.; Lübken, D.; Gatti, M.; Vailati Facchini, S.; Piarulli, U.; Pignataro, L.; Gennari, C. Improving $\mathrm{C}=\mathrm{N}$ Bond Reductions with (Cyclopentadienone)iron Complexes: Scope and Limitations. Eur. J. Org. Chem. 2019, 4, 647-654. [CrossRef]

47. Dou, X.; Hayashi, T. Synthesis of Planar Chiral Shvo Catalysts for Asymmetric Transfer Hydrogenation. Adv. Synth. Catal. 2016, 358, 1054-1058. [CrossRef]

48. Bai, X.; Cettolin, M.; Mazzoccanti, G.; Pierini, M.; Piarulli, U.; Colombo, V.; Dal Corso, A.; Pignataro, L.; Gennari, C. Chiral (cyclopentadienone)iron complexes with a stereogenic plane as pre-catalysts for the asymmetric hydrogenation of polar double bonds. Tetrahedron 2019, 75, 1415-1424. [CrossRef]

49. Zhou, S.; Fleischer, S.; Junge, K.; Beller, M. Cooperative Transition-Metal and Chiral Brønsted Acid Catalysis: Enantioselective Hydrogenation of Imines to Form Amines. Angew. Chem. 2011, 50, 5120-5124. [CrossRef] 
50. Fleischer, S.; Werkmeister, S.; Zhou, S.; Junge, K.; Beller, M. Consecutive Intermolecular Reductive Hydroamination: Cooperative Transition-Metal and Chiral Brønsted Acid Catalysis. Chem. Eur. J. 2012, 18, 9005-9010. [CrossRef]

51. Zhou, S.; Fleischer, S.; Jiao, H.; Junge, K.; Beller, M. Cooperative Catalysis with Iron and a Chiral Brønsted Acid for Asymmetric Reductive Amination of Ketones. Adv. Synth. Catal. 2014, 356, 3451-3455. [CrossRef]

52. Hopmann, K. Iron/Brønsted Acid Catalyzed Asymmetric Hydrogenation: Mechanism and Selectivity-Determining Interactions. Chem. Eur. J. 2015, 21, 10020-10030. [CrossRef] [PubMed]

53. Fleischer, S.; Zhou, S.; Werkmeister, S.; Junge, K.; Beller, M. Cooperative Iron-Brønsted Acid Catalysis: Enantioselective Hydrogenation of Quinoxalines and 2H-1,4-Benzoxazines. Chem. Eur. J. 2013, 19, 4997-5003. [CrossRef] [PubMed]

54. El-Sepelgy, O.; Brzozowska, A.; Rueping, M. Asymmetric Chemoenzymatic Reductive Acylation of Ketones by a Combined Iron-Catalyzed Hydrogenation-Racemization and Enzymatic Resolution Cascade. ChemSusChem 2017, 10, 1664-1668. [CrossRef] [PubMed]

55. Gustafson, K.P.J.; Gudmundsson, A.; Lewis, K.; Bäckvall, J.-E. Chemoenzymatic Dynamic Kinetic Resolution of Secondary Alcohols Using and Air- and Moisture-Stable Iron Racemization Catalyst. Chem. Eur. J. 2017, 23, 1048-1051. [CrossRef] [PubMed]

56. Mérel, D.S.; Gaillard, S.; Ward, T.R.; Renaud, J.-L. Achiral Cyclopentadienone Iron Tricarbonyl Complexes Embedded in Streptadivin: An Access to Artificial Iron Hydrogenases and Application in Asymmetric Hydrogenation. Catal. Lett. 2016, 146, 564-569. [CrossRef]

57. Kim, M.; Lee, J.W.; Lee, J.E.; Kang, J. Synthesis of Enantiopure Ruthenium Tricarbonyl Complexes of a Bicyclic Cyclopentadienone Derivative. Eur. J. Inorg. Chem. 2008, 16, 2510-2513. [CrossRef]

58. Funk, T.W.; Mahoney, A.R.; Sponenburg, R.A.; Zimmerman, K.P.; Kim, D.K.; Harrison, E.E. Synthesis and Catalytic Activity of (3,4-Diphenylcyclopentadienone)Iron Tricarbonyl Compounds in Transfer Hydrogenations and Dehydrogentations. Organometallics 2018, 37, 1133-1140. [CrossRef]

59. Cesari, C.; Sambri, L.; Zacchini, S.; Zanotti, V.; Mazzoni, R. Microwave-Assisted Synthesis of Functionalized Shvo-Type Complexes. Organometallics 2014, 33, 2814-2819. [CrossRef]

60. Moulin, S.; Dentel, H.; Pagnoux-Ozherelyeva, A.; Gaillard, S.; Poater, A.; Cavallo, L.; Lohier, J.-F.; Renaud, J.-L. Bifunctional (Cyclopentadienone)Iron-Tricarbonyl Complexes: Synthesis, Computational Studies and Application in Reductive Amination. Chem. Eur. J. 2013, 19, 17881-17890. [CrossRef]

61. Boss, C.; Keese, R. Synthesis of Cycloalkadiynes of Various Ring Size. Tetrahedron 1997, 53, 3111-3122. [CrossRef]

62. Weaving, R.; Roulland, E.; Monneret, C.; Florent, J.-C. A rapid acces to chiral alkylidene cyclopentenone prostaglandins involving ring-closing methathesis reaction. Tetrahedron Lett. 2003, 44, 2579-2581. [CrossRef]

63. Melikyan, G.G.; Voorhees, E.; Wild, C.; Spencer, R.; Molnar, J. Carbon tether rigidity as a stereochemical tool directing intramolecular cyclizations. Tetrahedron Lett. 2010, 51, 2287-2290. [CrossRef]

64. Matsuya, Y.; Ihara, D.; Fukuchi, M.; Honma, D.; Itoh, K.; Tabuchi, A.; Nemoto, H.; Tsuda, M. Synthesis and biological evaluation of pyrethroid insecticide-derivatives as a chemical inducer for Bdnf mRNA expression in neurons. Bioorg. Med. Chem. 2012, 20, 2564-2571. [CrossRef] [PubMed]

65. Šebesta, R.; Pizzuti, M.G.; Minnaard, A.J.; Feringa, B.L. Copper-Catalyzed Enantioselective Conjugate Addition of Organometallic Reagents to Acyclic Dienones. Adv. Synth. Catal. 2007, 349, 1931-1937. [CrossRef]

66. Pan, L.; Yang, K.; Li, G.; Ge, H. Palladium-catalyzed site-selective arylation of aliphatic ketones enabled by a transient ligand. Chem. Commun. 2018, 54, 2759-2762. [CrossRef] [PubMed]

67. Richard, C.J.; Macmillan, D.; Hogarth, G. Microwave-assisted synthesis of cyclopentadienone iron tricarbonyl complexes: Molecular structures of $\left[\left\{\eta^{4}-\mathrm{C}_{4} \mathrm{R}_{2} \mathrm{C}(\mathrm{O}) \mathrm{C}_{4} \mathrm{H}_{8}\right\} \mathrm{Fe}(\mathrm{CO})_{3}\right]\left(\mathrm{R}=\mathrm{Ph}, 2,4-\mathrm{F}_{2} \mathrm{C}_{6} \mathrm{H}_{3}, 4-\mathrm{MeOC}_{6} \mathrm{H}_{4}\right)$ and attempts to prepare $\mathrm{Fe}(\mathrm{II})$ hydroxycyclopentadienyl-hydride complexes. Transit. Met. Chem. 2018, 43, 421-430. [CrossRef]

68. Corey, E.J.; Venkateswarlu, A. Protection of hydroxyl groups as tert-butyldimethylsilyl derivatives. J. Am. Chem. Soc. 1972, 94, 6190-6191. [CrossRef]

69. Johnson, C.S.; Mottley, C. Theory of the temperature dependence of the NMR spectra of tunneling methyl groups. J. Phys. C Solid State Phys. 1976, 9, 2789-2795. [CrossRef] 
70. Sobieski, J.W. Assessing Steric Bulk of Protecting Groups Via A Computational Determination of Exact Cone Angle $\left(\theta^{\circ}\right)$ and Exact Solid Cone Angle $\left(\Theta^{\circ}\right)$. Ph.D. Thesis, Kent State University Honors College, Kent, $\mathrm{OH}$, USA, May 2018.

71. Xu, L.; Li, S.; Jiang, L.; Zhang, G.; Zhang, W. Electronic and steric effects of substituents in 1,3-diphenylprop-2-yn-1-one during ist reaction with $\mathrm{Ru}_{3}(\mathrm{CO})_{12}$. RSC Adv. 2018, 8, 4354-4361. [CrossRef]

72. Stevens, P.J.; Devlin, F.J.; Chablowski, C.F.; Frisch, M.J. Ab Initio Calculation of Vibrational Absorption and Circular Dichroism Spectra Using Density Functional Force Fields. J. Phys. Chem. 1994, 98, 11623-11627. [CrossRef]

73. Becke, A.D. A new mixing of Hartree-Fock and local density-functional theories. J. Chem. Phys. 1993, 98, 5648. [CrossRef]

74. Hay, P.J.; Wadt, W.R. Ab initio effective core potentials for molecular calculations. Potentials for K to Au including the outermost core orbitals. J. Chem. Phys. 1985, 82, 299-310. [CrossRef]

75. Huzinaga, S.; Anzelm, J.; Klobukowski, M.; Radzio-Andzelm, E.; Sakai, Y.; Tatewaki, H. Gaussian Basis Sets for Molecular Calculations; Elsevier: Amsterdam, The Netherlands, 1984.

76. Hach, V. Meerwein-Ponndorf-Verley Reduction of Mono- and Bicyclic Ketones. Rate of Reaction. J. Org. Chem. 1973, 38, 293-299. [CrossRef]

77. Tukacs, J.M.; Fridrich, B.; Dibó, G.; Székely, E.; Mika, L.T. Direct asymmetric reduction of levulinic acid to gamma-valerolactone: Synthesis of a chiral platform molecule. Green Chem. 2015, 17, 5189-5195. [CrossRef]

(C) 2019 by the authors. Licensee MDPI, Basel, Switzerland. This article is an open access article distributed under the terms and conditions of the Creative Commons Attribution (CC BY) license (http://creativecommons.org/licenses/by/4.0/). 